\title{
Metformin: an old medication of new fashion: evolving new molecular mechanisms and clinical implications in polycystic ovary syndrome
}

\author{
Evanthia Diamanti-Kandarakis, Charikleia D Christakou, Eleni Kandaraki ${ }^{1}$ and Frangiskos N Economou \\ Endocrine Section, First Department of Medicine, University of Athens Medical School, Mikras Asias 75, Goudi 115-27, Athens, Greece and \\ ${ }^{1}$ Department of Medicine, Hull Royal Infirmary, Anlaby Road, Hull, HU3 2JZ England, UK
}

(Correspondence should be addressed to E Diamanti-Kandarakis; Email: akandara@otenet.gr)

\begin{abstract}
Polycystic ovary syndrome (PCOS) is now recognized to be the most common endocrinopathy in women of reproductive age with a prevalence of 6.6-6.8\%. PCOS, a syndrome of unknown etiology, was initially regarded as a reproductive disorder. However, in the last 15 years the role of insulin resistance (IR) has been identified as a significant contributor to the pathogenesis of PCOS, and the metabolic and cardiovascular sequelae of the syndrome have been increasingly appreciated. The coexistence and interaction of reproductive and cardiometabolic abnormalities in the context of PCOS have created a need for a modified therapeutic management of affected women.

Insulin sensitizers, particularly metformin, have been introduced as a pharmaceutical option targeting not only IR, but several other aspects of the syndrome, including reproductive abnormalities. The landscape of the multifaceted actions of metformin evolves to broaden the therapeutic implications of this old drug in a new fashion for patients with PCOS. Most recently, the spectrum of metformin's targets has been expanded, and molecular studies have explored the tissue-specific mechanisms of metformin in the liver, the muscle, the endothelium, and the ovary. The use of metformin in pregnant women with PCOS comprises another scarcely explored, but promising area of research. This review attempts to cover the spectrum of metformin's cellular actions in different tissues and to summarize the current literature regarding the potential medical value of this medication in PCOS. Even if many of these actions are individually modest, they seem to be collectively sufficient to confer therapeutic benefits not only in cardiometabolic aspects but also in reproductive aspects of PCOS.
\end{abstract}

European Journal of Endocrinology 162 193-212

\section{Introduction}

The polycystic ovary syndrome (PCOS) is a common endocrinopathy, affecting $6.8 \%$ of reproductive-aged women (1). PCOS was initially regarded as a reproductive disorder afflicting women from postmenarche throughout the premenopausal period. Anovulation and androgen excess have been considered the hallmark diagnostic criteria of the syndrome. However, during the last 15 years insulin resistance (IR) has been identified as a significant contributor to the pathogenesis of PCOS. IR has been demonstrated to participate in the reproductive as well as metabolic abnormalities associated with PCOS (2). Increasingly appreciated are the metabolic and cardiovascular sequelae of the syndrome. The expanding knowledge in the pathophysiology and clinical spectrum of PCOS has created a need for a modified therapeutic management of affected women. The research focus has been placed on the discovery of effective pharmaceutical tools for the global therapeutic management of this multicomponent syndrome.
A pathophysiologically rationalized therapeutic approach should take into account the fact that reproductive and cardiometabolic abnormalities coexist and interact with each other in the context of PCOS. Therefore, insulin sensitizers, particularly metformin, have been introduced as a pharmaceutical option targeting not only IR, but several other aspects of the syndrome, including reproductive abnormalities (3).

\section{Mechanisms of actions of metformin in different tissues}

The biguanide, metformin, is the most widely prescribed insulin sensitizer in the therapeutic management of type 2 diabetes (T2D). Metformin exerts its principal metabolic action and especially its glucoregulatory action upon the liver (Fig. 1). Interest in the therapeutic use of metformin has been sparked by the recognition of its pleiotropic actions on several tissues, which are affected by IR and/or hyperinsulinemia (3). 


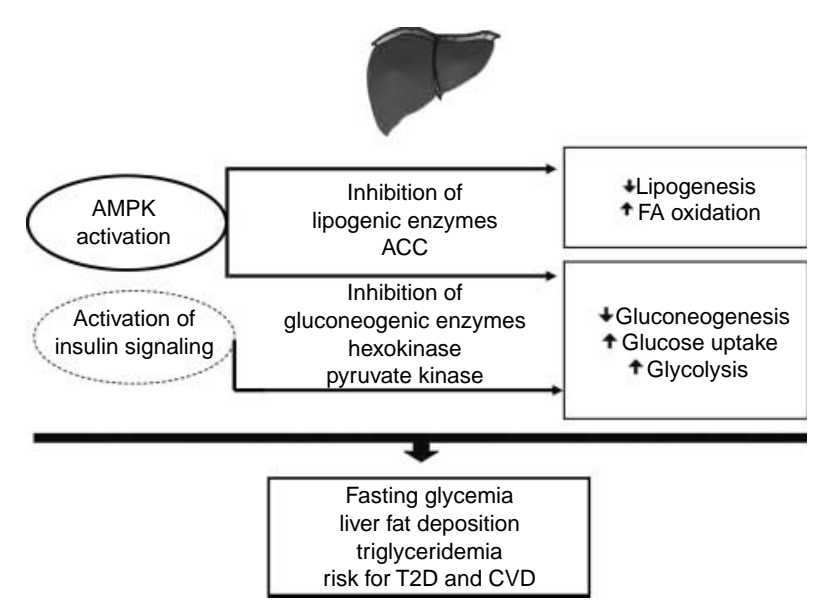

Figure 1 Actions of metformin in the liver: molecular mechanisms, effects on metabolic processes, and clinical corollaries. Metformin exerts direct effects on hepatic glucose and lipid metabolism. Metformin suppresses gluconeogenesis mainly through AMPKdependent activation of key enzymes, whereas it enhances glucose uptake and glycolysis through the activation of hexokinase and pyruvate kinase. The enhancement of insulin signaling may play a part in the latter effect. In addition, metformin suppresses lipogenic enzymes, particularly acetyl-CoA carboxylase (ACC) activity via an AMPK-dependent pathway, thus leading to decreased lipogenesis but increased fatty acid oxidation. The net benefits of the above hepatic actions of metformin appear to be the decrease of fasting glucose and triglyceride levels and the diminution of liver fat content. - - - potential or questionable action; $\uparrow$, stimulation or increase; $\downarrow$, inhibition or decrease; ACC, acetyl-CoA carboxylase; AMPK, $5^{\prime}$-AMP-activated protein kinase; FAs, fatty acids; TG, triglycerides.

Although the liver is the primary target organ, metformin acts on a variety of tissues, namely skeletal muscles, adipose tissue, endothelium, and the ovary.

\section{Action in liver}

The metformin-induced inhibition of hepatic gluconeogenesis has been ascribed to several mechanistic cascades. Potential mechanisms are the direct inhibition of gluconeogenic enzymes (e.g. phosphoenolpyruvate carboxykinase, fructose-1,6-bisphosphatase, and glucose-6-phosphatase), the reduced hepatic uptake of substrates for gluconeogenesis, and the increased phosphorylation of insulin receptor and insulin receptor substrates (IRS)-1 and -2 (4-9). Other investigators have also demonstrated the inhibition of mitochondrial respiration by metformin, which may reduce the energy supply required for gluconeogenesis (10). In counterbalance, metformin stimulates glucose entry into the liver and glycolysis through the activation of glycolytic enzymes, such as hexokinase (glucokinase) and pyruvate kinase $(5,11)$.

A clinical study in type 2 diabetics showed that treatment with metformin increases insulin-mediated hepatic glucose uptake. The concomitant increase of visceral fat glucose uptake may enhance reesterification of free fatty acids (FFAs) through augmented glycolytic generation of glycerolphosphate. Increased FFA reesterification in visceral adipose tissue reduces lipolysis and FFA delivery to the liver, possibly leading to decreased hepatic gluconeogenesis (12).

In addition, metformin suppresses acetyl-CoA carboxylase (ACC) activity $(5,13,14)$. ACC is an important rate-controlling enzyme for the synthesis of malonyl-CoA, which is both a critical precursor of FAs and a potent inhibitor of mitochondrial FA oxidation. Inhibition of ACC reduces malonyl-CoA content and subsequently leads to decreased FA synthesis and increased mitochondrial FA oxidation via the allosteric regulation of carnitine palmitoyltransferase-1, which catalyzes the entry of long-chain fatty acyl-CoA into mitochondria. Thus, the metformin-induced suppression of hepatic ACC appears to regulate the partitioning of FA between oxidative and biosynthetic pathways. The net benefit is the diminution of intracellular hepatic lipid content, thus preventing hepatic steatosis, as well as the reduction of plasma triglyceride levels (15).

Stimulation of $5^{\prime}$-AMP-activated protein kinase (AMPK) appears to be a key mediator of metformin's actions on hepatic gluconeogenesis and lipogenesis (14, 16). Metformin was shown to inhibit hepatic gluconeogenesis by modulating the AMPK-dependent regulation of the orphan nuclear receptor small heterodimer partner (17). The serine-threonine protein kinase 11 (SK11), alternatively termed LKB1, has been reported to be an upstream AMPK activator in the metformininduced hepatic pathway. The SK11/AMPK signals are then involved in the suppression of genes encoding gluconeogenic and lipogenic liver enzymes (18). To suppress the expression of gluconeogenic genes, AMPK deactivates the coactivator transducer of regulated CREB activity (TORC2) leading to the suppression of the cAMP-inducible transcription factor CREB (19).

\section{Action in skeletal muscle}

Skeletal muscle accounts for more than $80 \%$ of insulinstimulated glucose uptake. Therefore, it is important to discuss the action of metformin, an insulin sensitizer, on this tissue (Fig. 2).

In cultures of insulin-resistant skeletal muscle cells, metformin was able to restore insulin signaling defects, including the reductions in insulin-stimulated insulin receptor and IRS-1 phosphorylation and in phosphatidylinositol-3 kinase (PI3K) activity (20). In this study, metformin increased basal glucose uptake in a p38 MAP kinase (MAPK)-dependent mode, but it failed to restore insulin-stimulated glucose transport, which was impaired by chronic insulin treatment. However, there should be a cautionary note regarding the fact that metformin concentrations required for such in vitro responses were much higher $(400 \mu \mathrm{mol} / \mathrm{l})$ than the therapeutic doses in humans $(10-30 \mu \mathrm{mol} / \mathrm{l})$. This fact may account for the failure of in vivo studies to replicate the above effects of metformin on PI3K activity in 


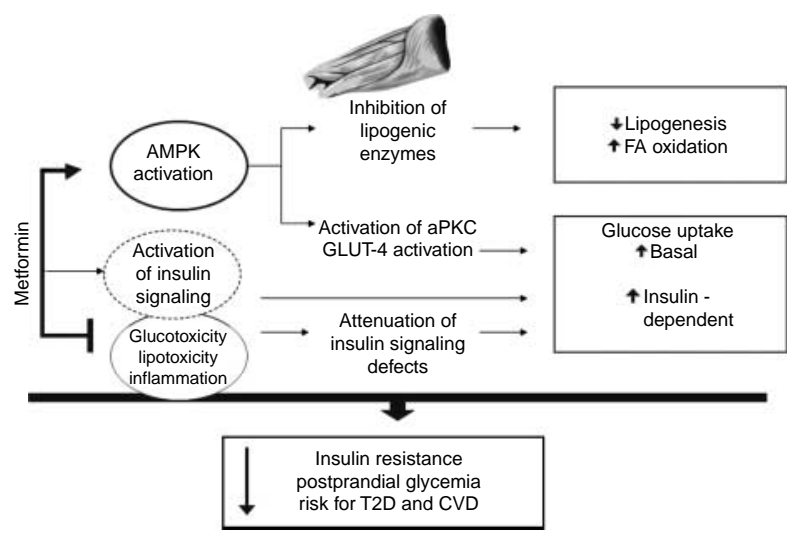

Figure 2 Actions of metformin on skeletal muscle: molecular mechanisms, effects on metabolic processes, and clinical corollaries. In skeletal muscle, metformin may moderately increase basal and insulin-stimulated glucose uptake. The former effect appears to be mediated by AMPK activation and subsequent aPKC and GLUT-4 activation, while the latter effect may involve the enhancement of insulin signaling either directly or indirectly through the attenuation of glucotoxicity, lipotoxicity, and inflammation. By activating AMPK, metformin may also inhibit lipogenesis, while enhancing fatty acid oxidation in skeletal muscle. The net result of the above actions may be the attenuation of systemic insulin resistance and the decrease of postprandial glucose levels. $\uparrow$, stimulation or increase; $\downarrow$, inhibition or decrease; AMPK, $5^{\prime}$-AMP. activated protein kinase; FAs, fatty acids, GLUT-4, glucose transporter-4; PKC, protein kinase C.

skeletal muscle of humans with T2D (21). However, at physiologically relevant concentrations $(20 \mu \mathrm{mol} / \mathrm{l})$ metformin retained its capacity to increase insulinstimulated glycogen synthesis in cultured human myotubes (22).

Furthermore, there is evidence of acute and chronic effects of metformin treatment on lipid metabolism and turnover in skeletal muscle. Chronic metformin treatment was reported to impede lipid accumulation in human skeletal muscle $(23,24)$. Acute metformin treatment was shown to prevent the insulin-induced suppression of FA oxidation in oxidative muscles, while blunting the incorporation of FA into triacylglycerol in glycolytic muscle fibers in rodents (25). Accordingly, in soleus muscle homogenates from female Zucker diabetic fatty rats, metformin reduced the total ceramide and diacylglycerol muscle content induced by a high-fat diet (26). Such lipid effects could contribute to improved insulin sensitivity and insulin-stimulated glucose uptake, although such an improvement was not noticeable in the latter model (26).

To date, it remains unsettled whether and to what extent metformin improves skeletal muscle insulin sensitivity (27). The beneficial effect of metformin on muscle glucose utilization may be attributed either to attenuation of gluco- and lipotoxicity, which inhibit insulin signaling or to insulin-independent activation of the AMPK pathway. More specifically, metformin increases AMPK activity in muscles of diabetic subjects (28). AMPK activation in skeletal muscle induces atypical protein kinase $\mathrm{C}$ (aPKC) isoforms, which promote glucose transporter-4 (GLUT-4) translocation to the plasma membrane and glucose transport (29).

Correspondingly, in skeletal muscle from humans with T2D, chronic metformin treatment increased basal and insulin-stimulated aPKC activity without altering basal and insulin-stimulated activation of IRS-1-dependent PI3K and Akt (also known as protein kinase B, PKB) (30). Metformin has also been shown to increase mRNA and protein levels of GLUT-4 in soleus muscle from rats with streptozotocin-induced diabetes (7). In the latter model, metformin's action was mediated by the activation of opioid $\mu$-receptors via increased adrenal secretion of $\beta$-endorphin (7).

\section{Action in adipose tissue}

Adipose tissue has been recognized as an endocrine organ with a pivotal role in the regulation of insulin sensitivity and energy homeostasis. Its dysfunction contributes to the pathophysiology of the metabolic syndrome as well as of PCOS. Therefore, this organ may be an important therapeutic target in the management of these disorders.

Adipose tissue is not a major site of metformin's action; however, metformin appears to have modest effects on this tissue (Fig. 3). An older in vitro study has examined how metformin affects metabolic pathways in preadipocytes. Overall, metformin was shown to stimulate catabolism, as reflected by increases in glucose transport and utilization, mitochondrial and peroxisomal FA $\beta$-oxidation, basal lipolysis, and aerobic and anaerobic respiration (i.e. lactate production). These effects were all independent of insulin. The caveat is that findings in preadipocytes cannot be safely extrapolated to mature adipocytes (31).

A more recent study using subcutaneous fat specimens examined the effect of adding metformin ( $2.550 \mathrm{mg} /$ day for $3-4$ months) in type 2 diabetics failing sulfonylurea monotherapy. In subcutaneous abdominal fat biopsies obtained from these subjects, metformin failed to affect glucose transport. In addition, the drug had no effect on expression/activation of IRS-1; its downstream effectors, PI3K and Akt (or PKB); and the final effector, GLUT-4 (32). However, using positron emission tomography with [18F]fluorodeoxyglucose other investigators have separately studied the effects of metformin on visceral and subcutaneous adipose tissue. More specifically, chronic metformin treatment of type 2 diabetics significantly enhanced glucose uptake in visceral fat depot, although such an effect was not demonstrable in specimens from femoral subcutaneous adipose tissue $(12,33)$.

Although the effect of metformin on insulin-stimulated glucose transport in adipose tissue remains disputable, there are data supporting that it affects adipose tissue lipolysis. In primary rat adipocytes stimulated with tumor necrosis factor- $\alpha$ (TNF- $\alpha$ ), 


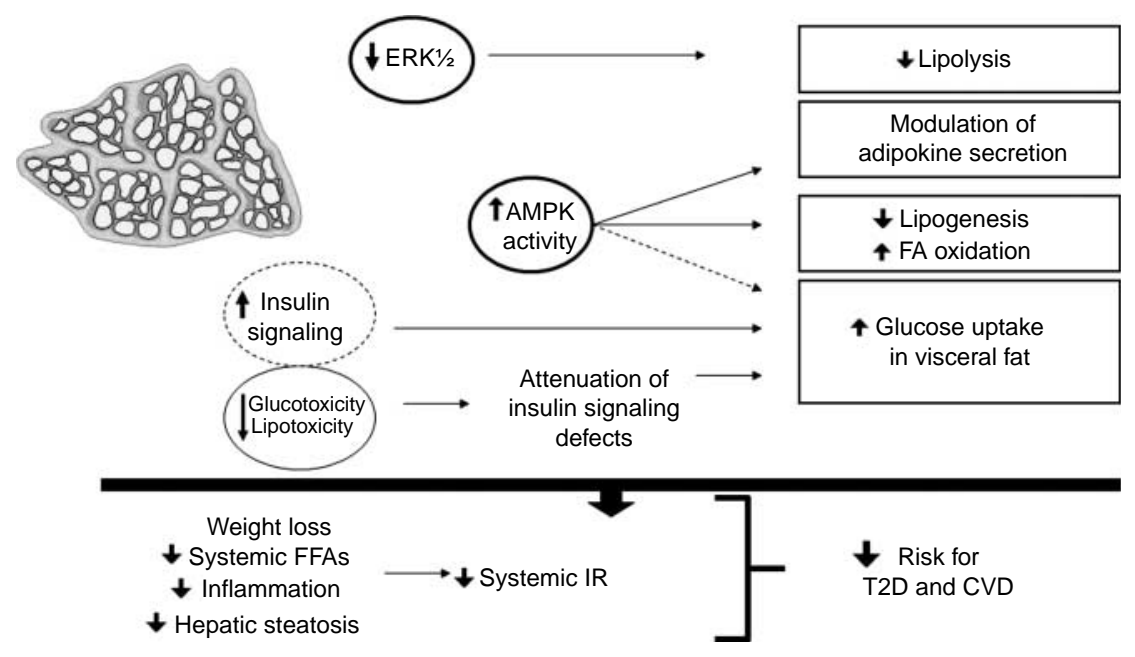

Figure 3 Actions of metformin on the adipose tissue: molecular mechanisms, effects on metabolic processes, and clinical corollaries. Metformin may inhibit agonist-induced lipolysis in adipocytes via inhibition of ERK1/2 phosphorylation, but it may counteract adipose tissue expansion through AMPK-dependent stimulation of FA oxidation and inhibition of lipogenesis in subcutaneous fat depot. This antiadipogenic effect may contribute to reduced fat mass. The antilipolytic action of metformin could contribute to insulin sensitization through the decrease of systemic FFA levels. The contribution of metformin to the attenuation of glucotoxicity and lipotoxicity may further improve insulin sensitivity in adipose tissue. An AMPK-dependent mechanism may also enhance glucose uptake by visceral adipose tissue. Metformin may also modulate adipokine secretion through molecular pathways, which appear to differ between individual adipokines and may involve either p44/p42 MAPK or AMPK. - - , potential or questionable action; $\mathbf{\uparrow}$, stimulation or increase; $\downarrow$, inhibition or decrease; AMPK, 5'-AMP-activated protein kinase; FFAs, free fatty acids; IR, insulin resistance; MAPK, MAP kinase.

isoproterenol, and/or high glucose concentrations, metformin was shown to inhibit lipolysis. Inhibition of phosphorylation of ERK1/2 was involved in the attenuation of TNF- $\alpha$-mediated lipolysis by metformin. This antilipolytic action could contribute to the insulinsensitizing effect of metformin through the decrease of systemic FFA levels (34).

Moreover, metformin may counteract adipose tissue expansion through direct inhibition of adipogenesis. Culturing preadipocytes in the presence of metformin was found to inhibit intracellular lipid accumulation through phosphorylation of AMPK at threonine 172. This observation may have relevance in the potential weight-reducing effect of metformin (35). However, in vivo studies did not confirm the above-described role of metformin in adipogenesis. More specifically, in subcutaneous adipose tissue biopsies from humans with impaired glucose tolerance (IGT), metformin treatment (10-16 weeks, $2000 \mathrm{mg} /$ day) failed to affect gene expression of lipogenic enzymes, namely acylcoenzyme A:diacylglycerol transferase, fatty acid synthetase, and lipoprotein lipase (36).

More important than a reduction of total or subcutaneous fat mass is the potential specific role of metformin on visceral fat mass. However, most studies in subjects with IGT and T2D have failed to corroborate such an effect (37-40). Several investigators have ascribed the metformin-induced attenuation of central adiposity and weight loss to the loss of subcutaneous fat rather than of visceral fat (41).
Metformin may also impact on the endocrine function of adipose tissue through the modulation of adipokine synthesis or secretion. Leptin is the prototypic adipocytederived hormone inducing a negative energy balance. In a brown adipocyte model, metformin dose dependently inhibited leptin secretion through the stimulation of p44/p42 MAPK, independently of the PI3K signal. This selective molecular mechanism was suggested to contribute to an anorexigenic effect of this compound (42). Adiponectin is another adipokine with insulinsensitizing and anti-inflammatory properties. An in vitro study described that metformin inhibits adiponectin protein expression and release by mature adipocytes through AMPK activation (43). However, another in vitro study in 3T3-L1 adipocytes (44) as well as studies in $\mathrm{db} / \mathrm{db}$ mice (45) and in humans with T2D has not provided confirmatory data $(46,47)$. Even if present, the effect of metformin on adiponectin appears to be independent of the insulin-sensitizing effect of this drug (45). Visfatin is another adipokine with insulin-mimetic properties, which has been studied in metformin-treated obese subjects with IGT. Metformin was found to lack any effect on mRNA visfatin levels measured in subcutaneous fat biopsies from these subjects (48).

At the molecular level, activation of AMPK is a speculative mechanism whereby metformin could affect adipose tissue (49). More specifically, metformin activates AMPK in adipose tissue, as it does in other tissues. Interestingly, AMPK modulation by metformin was implicated in counteracting the obesogenic effects of 
corticosteroids in human adipose tissue. Metformin was shown to reverse the corticosteroid-induced suppression of AMPK activity in primary cultures of human adipocytes (50).

Glycogen synthase kinase-3 (GSK-3), a kinase implicated in insulin action and adipogenesis, has been explored as a potential mediator of metformin's action. However, in subcutaneous adipocytes from obese type 2 diabetics, a 3-4-month metformin therapy had no significant impact on the expression and serine phosphorylation of GSK-3 (51).

\section{Action in the ovary}

An intriguing area is the reproductive effects of treatment in women with PCOS. As discussed below, long-term metformin treatment may increase ovulation, improve menstrual cyclicity, and reduce serum androgen levels in these patients (52).

Metformin appears to affect ovarian function in a dual mode, through the alleviation of insulin excess acting upon the ovary and through direct ovarian effects. The potential direct effects of metformin on the ovary have been explored in the cultures of ovarian cells.

Regarding the action of metformin on theca cells, clinical data demonstrate reduced CYP17 activity in women with PCOS treated with this agent (53). An original clinical study has ascribed this effect to the lowering of insulin levels following metformin therapy. More specifically, insulin was shown to directly stimulate several steroidogenic enzymes in the ovary (17 $\alpha$-hydroxylase/17,20-lyase (CYP17) and $3 \beta$-hydroxysteroid dehydrogenase (3 $\beta$-HSD), P450 side-chain cleavage (P450scc), and StAR protein) (54) (Fig. 4).

In addition, in human ovarian theca-like tumor cells, metformin, at therapeutic concentrations, was able to suppress androstenedione (A4) production. This observation indicated a direct, insulin-independent action of metformin on theca cell steroidogenesis. Since the inhibition of A4 predominated over the inhibition of 17-hydroxyprogesterone, metformin was suggested to preferentially suppress CYP17 lyase over CYP17 hydroxylase activity (55).

In rat granulosa cells, metformin treatment was shown to reduce basal and FSH-stimulated progesterone and estradiol $\left(\mathrm{E}_{2}\right)$ production. In particular, metformin decreased FSH-stimulated $3 \beta$-HSD, StAR, CYP11A1, and aromatase (CYP19A1) protein expression, while inhibiting granulosa cell proliferation (56).

Although the dose of metformin in the aforementioned study (56) was many times higher than the classic doses used in humans, the findings in rat granulosa cells concur with human studies. Specifically, metformin treatment leads to decreased basal or FSH-stimulated progesterone and $\mathrm{E}_{2}$ concentrations in women with PCOS and in cultured human granulosa cells from women with or without PCOS (57-59).

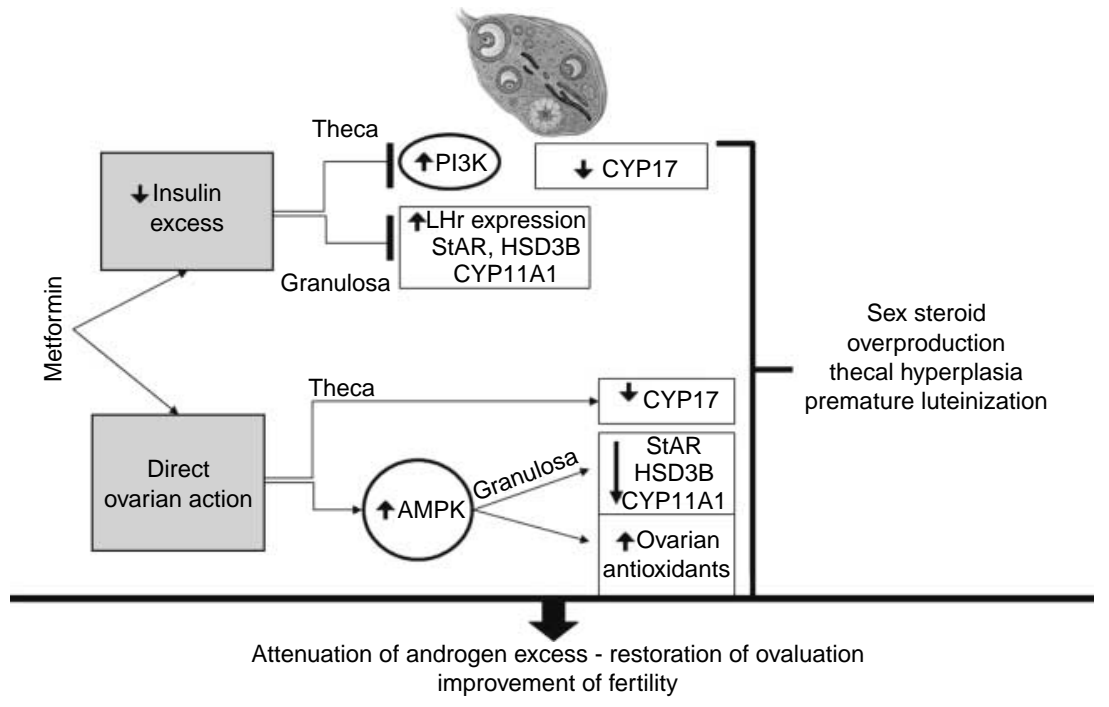

Figure 4 Actions of metformin on the ovary: molecular and pathophysiological mechanisms and clinical corollaries. Metformin may act upon the ovary either directly or indirectly by inhibiting the effects of insulin excess on steroidogenesis and follicular growth. In theca cells, metformin may inhibit CYP17 activity either through direct action or indirectly through the reduction of insulin levels and the subsequent suppression of insulin-induced PI3K activity. By reducing insulin levels, metformin may inhibit LH receptor expression as well as StAR, HSD3- $\beta$, and CYP11A1 activity in granulosa cells. In addition, metformin-induced AMPK activation may not only decrease StAR, HSD3- $\beta$, and CYP11A1 activity in granulosa cells, but also enhance antioxidant defenses at the ovarian tissue level. These mechanisms may contribute to the inhibition of sex steroid overproduction and of premature luteinization (due to premature LH receptor expression), and consequently attenuate androgen excess and improve ovulation. $\neq$ or -1 , inhibition; AMPK, $5^{\prime}$-AMP-activated protein kinase; CYP11A1, P450 side-chain cleavage (P450scc); CYP17, 17,20-lyase/17-hydroxylase; HSD3B, $3 \beta$ hydroxysteroid dehydrogenase; LHr, LH receptor; PI3K, phosphatidylinositol-3 kinase; StAR, StAR protein. 
However, the direct effects of metformin on ovarian steroidogenesis have not been confirmed in the "humanized yeast system', which expresses human steroidogenic enzymes in microsomal environments (60).

The molecular pathways whereby metformin may exert its potential direct actions on the ovary remain elusive. Searching for clues to this enigma, Tosca et al. have shown that metformin treatment induced AMPK activation in rat granulosa cells, accompanied by reduced steroid production (56). AMPK activation has also been associated with the ability of metformin to prevent the diminution of antioxidant defenses induced by hyperandrogenization with DHEA in prepubertal $\mathrm{BALB} / \mathrm{c}$ mice (61). Since AMPK subunits are abundantly expressed in rat ovary (oocyte, corpus luteum, granulosa, and theca cells) (62), AMPK may contribute to several ovarian processes and mediate metformin's action on the ovary.

\section{Action on endothelium}

Endothelium is a major target of insulin, and endothelial function is considered to mirror the state of insulin sensitivity in vascular tissue (63). A principal cardiovascular action of insulin is the stimulation of endothelial production of the potent vasodilator nitric oxide (NO) through a PI3K-mediated mechanism. Using distinct MAPK-dependent pathways, insulin also stimulates endothelial vasoconstrictor, endothelin-1 (ET-1), adhesion molecules (vascular cell adhesion molecule-1, E-selectin, and intercellular adhesion molecule-1), and plasminogen activator inhibitor-1 (PAI-1). IR is characterized by selective impairment of PI3K-dependent signaling and subsequent inhibition of insulin-induced vasodilation, whereas the MAPK-dependent insulin actions are overactivated. Insulin excess resulting from IR acts through the latter pathway to preferentially promote MAPK-dependent effects (63).

Overall, the coupling between metabolic and cardiovascular actions of insulin plays an important role in linking metabolic and cardiovascular pathophysiology. The improvement of metabolic IR by insulin sensitizers tends to be paralleled by a simultaneous alleviation of endothelial dysfunction. In particular, metformin was reported to improve endothelium-dependent vasodilation in insulin-resistant patients, thus potentially protecting against atherogenesis (63).

Most intriguingly, this drug appears to have direct beneficial effects on endothelium, beyond glucose lowering and insulin sensitization (Fig. 5). At the molecular level, metformin was shown to promote activation of endothelial NO synthase (eNOS) in cultured bovine aortic endothelial cells (64). In human endothelial cells, metformin was also shown to prevent high glucose-induced cell death. This effect was ascribed to the inhibition of mitochondrial respiration and inactivation of an oxidative stress-sensitive channel,

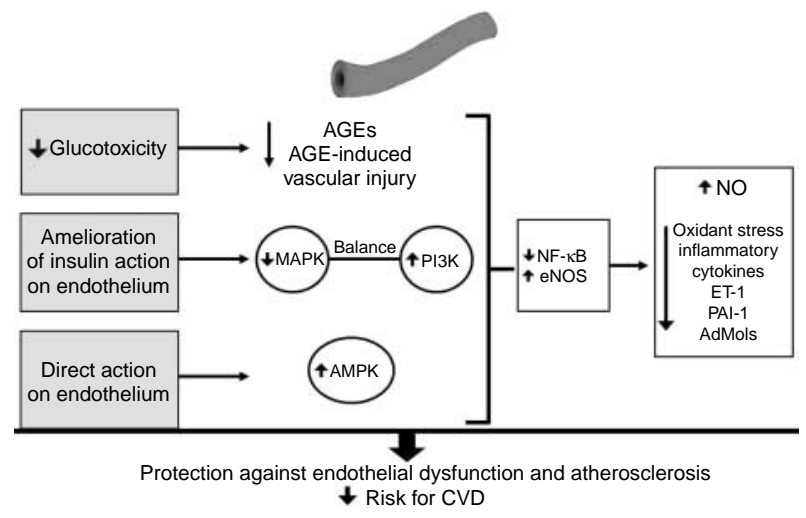

Figure 5 Actions of metformin on endothelium: molecular mechanisms, effects on vascular function, and clinical corollaries. Metformin's action on the vasculature depends significantly upon the inhibition of glucotoxicity and the reduction of circulating levels of advanced glycated end products as well as upon the alleviation of insulin resistance/hyperinsulinemia. At the molecular level, these mechanisms synergize to establish a more favorable balance between the MAPK- and the PI3K-dependent cascades. Metformin also appears to have direct beneficial effects on endothelium, mediated by AMPK activation, independently of glucose lowering and insulin sensitization. As a result, metformin treatment may suppress NF- $\kappa \beta$, thus reducing the production of proinflammatory cytokines, ET-1, PAI-1, and adhesion molecules, while it may enhance eNOS and NO production in endothelial cells. Through these mechanisms metformin may contribute to the amelioration of endothelial function and deceleration of atherosclerotic injury. AdMols, adhesion molecules; AGEs, advanced glycated end products; AMPK, 5'-AMP-activated protein kinase; eNOS, endothelial nitric oxide synthase; ET-1, endothelin-1, NF- $\kappa B$, nuclear factor-кB; NO, nitric oxide; PAI-1, plasminogen activator inhibitor-1.

rendering the outer mitochondrial membrane less permeable to pro-apoptotic proteins (65).

Furthermore, metformin attenuated nuclear factor (NF)- $\kappa \mathrm{B}$ activation in human umbilical vein endothelial cells (HUVECs) exposed to inflammatory cytokines. This effect was accompanied by reduced expression of genes encoding proinflammatory and adhesion molecules in HUVECs (66). A subsequent in vitro study has confirmed that metformin at clinically relevant concentrations inhibited TNF- $\alpha$-induced NF- $\mathrm{BB}$ pathway activation and IL-6 production (67).

As in liver and skeletal muscle, AMPK may also mediate metformin's action on endothelium. AMPK activation was shown to mediate eNOS activation and NF- $\kappa$ B inhibition in bovine aortic endothelial cells and in HUVECs $(64,66)$. In addition, AMPK activation may reduce the FFA content by stimulating fat oxidation in endothelial cells, while it may also suppress de novo synthesis of diacylglycerol by inhibiting glycerol-3phosphate acyltransferase. Thereby, AMPK activation can alleviate endothelial lipotoxicity, which is known to contribute to increased superoxide production and impaired NO activity (68).

The mechanism of metformin-induced AMPK activation in endothelium remains under investigation. Serine phosphorylation of LKB1 by PKC zeta was 
found to be required for metformin-induced phosphorylation/activation of AMPK in both HUVECs and bovine aortic endothelial cells (69). In cultured bovine aortic endothelial cells, AMPK activation by metformin was associated with increased mitochondria-derived reactive nitrogen species. In these cells, activation of the c-Src/PI3K pathway was suggested to generate an intracellular promoter of AMPK by the LKB1 complex (70). Accordingly, PI3K-dependent activation of AMPK in human endothelial cells may account for the inhibitory effect of metformin on the TNF- $\alpha$-induced NF-кB pathway (67).

\section{Metformin in PCOS}

\section{Effects on reproductive abnormalities in PCOS}

Metformin therapy targeting conception: anovulation, subfertility, and pregnancy outcomes The first study reporting the beneficial effects of metformin on reproductive as well as metabolic aberrations of PCOS was published in 1994 in the United States (71). This study found that a 2-month metformin treatment in 26 obese PCOS led to the attenuation of hyperinsulinemia, reduction of androgen levels, and regularization of menses (71). Two years later, administration of metformin to women with PCOS was shown to decrease ovarian 17,20-lyase activity and ovarian androgen secretion, while lowering insulin levels (53).

Since then, a slew of clinical studies have addressed the impact of metformin treatment on hyperandrogenemia in women with PCOS. Most, but not all, studies have confirmed that metformin treatment for at least 6 months reduces androgen levels in women with PCOS (72).

The capacity of metformin to attenuate both IR and androgen excess, at least in some patients, has rationalized the investigation of metformin's role in the management of reproductive failure in PCOS women. The potential direct actions of metformin on ovarian function, unveiled by in vitro studies, may also contribute to its effects on reproductive aspects (see 'Metformin in PCOS' subsection 'Predictors of response to metformin').

Metformin either alone or in combination with clomiphene citrate (CC) is a pharmaceutical option for ovulation induction in women with PCOS (73) (Table 1). Metformin monotherapy, as compared to placebo, has been shown to improve ovulation rates in women with PCOS in randomized controlled trials (RCTs), cohort studies, or uncontrolled descriptive studies. However, only few of them had pregnancy as a defined outcome measure (74). Relevant data have been summarized by a meta-analysis and several reviews (74-77) (Table 1$)$.

Moreover, small studies have found higher or similar ovulation and pregnancy rates following metformin treatment as compared to the ones following CC administration (78-80), while the addition of metformin to CC monotherapy was reported to further enhance ovulation rates in a meta-analysis (74) (Table 1). However, most studies involved small and phenotypically heterogeneous groups and did not draw any distinction between therapy-naive and CC-resistant women. Most importantly, the majority of studies relied on ovulation rates as a surrogate for live birth rates $(81)$.

Most recently, the key question has been raised as to whether metformin or metformin plus CC are superior to $\mathrm{CC}$ alone in terms of primary reproductive endpoints. The live birth rate is the most clinically meaningful outcome (81). A double-blind RCT in 100 nonobese women with PCOS demonstrated a trend for superiority of metformin versus CC in terms of live birth (Table 1). However, a subsequent double-blind RCT in a larger sample of PCOS women did not confirm this trend (82). This trial (82) assessed live birth rate as a primary endpoint and reported that metformin is inferior to CC. In that study, although the addition of metformin to $\mathrm{CC}$ led to a higher ovulation rate, this increase did not translate into a higher live birth rate. These findings are compelling in view of the sizeable study population, multicenter recruitment, consistency of group differences over a broad body mass index (BMI) range, use of a live birth endpoint, and overall methodologic rigor (82). However, neither this study drew the distinction between therapy-naive and CC-resistant patients. In accordance with the study by Legro et al. (82), another RCT in Dutch infertile women with PCOS has shown that metformin added to $\mathrm{CC}$ failed to improve rates of pregnancy (83).

In the light of these novel data, Moll et al. have conducted a meta-analysis aiming to unveil potential differences in the response to infertility treatment between therapy-naive and CC-resistant patients with PCOS (84) (Table 1). In therapy-naive patients, comparison of treatment arms did not show any benefit of adding metformin to $\mathrm{CC}$ over $\mathrm{CC}$ alone in terms of live birth. However, in CC-resistant women combined treatment with metformin and $\mathrm{CC}$ led to higher live birth rate as compared to the one achieved with $\mathrm{CC}$ monotherapy (84).

These novel data have been viewed as a rationale for the shift toward $\mathrm{CC}$ as the first-line treatment for achieving conception, pregnancy and live birth in therapy-naive women with PCOS. However, the everpresent risk of multiple pregnancies with $\mathrm{CC}$, but not with metformin, should not be overlooked (82). Most importantly, metformin still holds its own role in the pharmaceutical treatment of infertility in PCOS. Although the recent 'Thessaloniki consensus paper' recommended that metformin use in PCOS should be restricted to women with glucose intolerance (85), other experts in the field argue that this drug has a broader therapeutic utility. Although CC is recognized 
Table 1 Randomized clinical studies and meta-analyses addressing the efficacy of metformin versus placebo in women with polycystic ovary syndrome (PCOS; in parameters assessed as primary outcome measures).

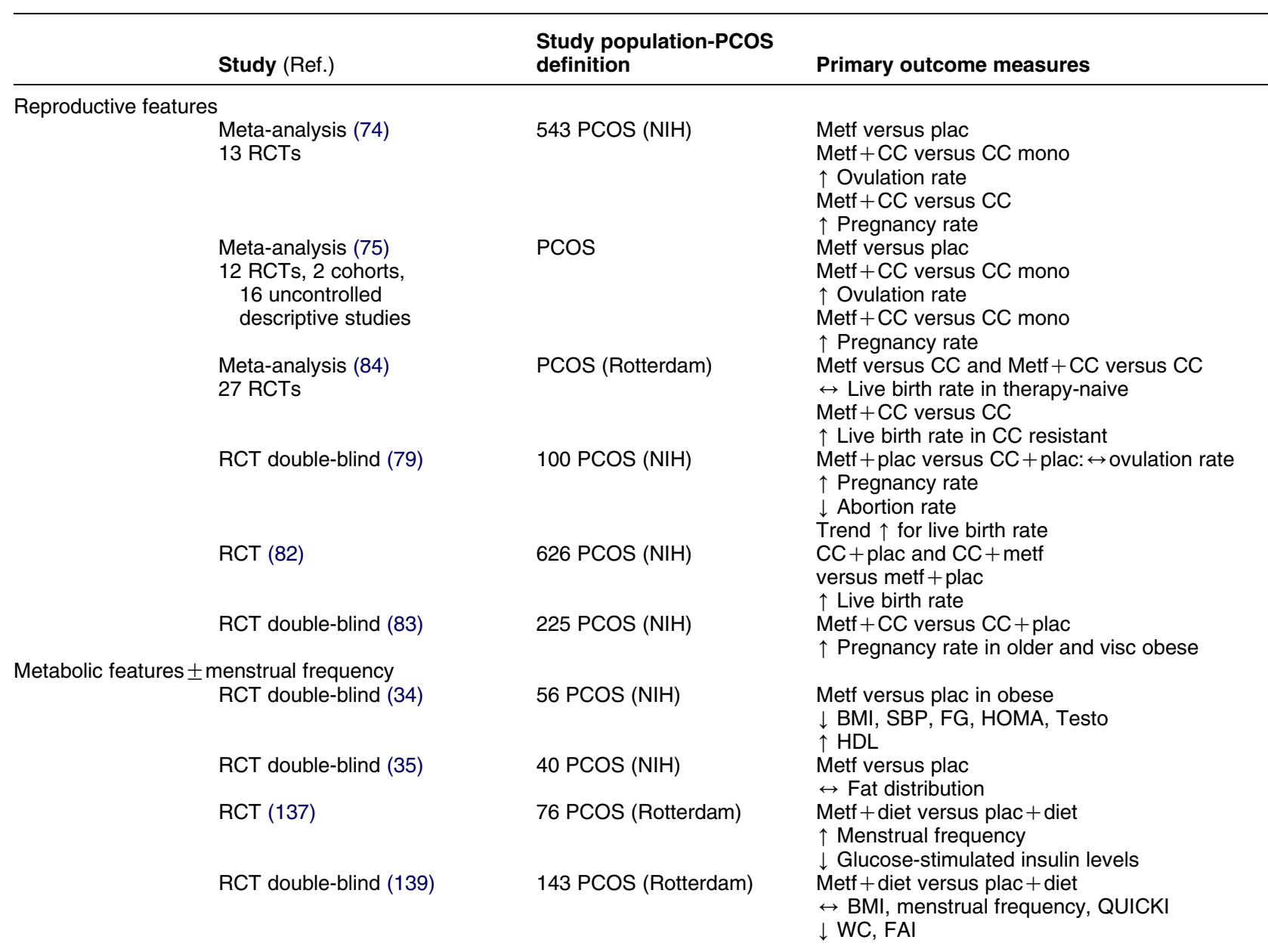

FAI, free androgen index; FG, fasting glucose; Plac, placebo; Testo, testosterone; Visc, viscerally; WC, waist circumference; $\uparrow$, increase; $\downarrow$, decrease; $\leftrightarrow$, no difference.

as the first-line agent in women with PCOS who desire immediate pregnancy, addition of metformin may be beneficial to specific subgroups of such women, like those with CC resistance (84) or those who are older and viscerally obese (86). Moreover, metformin appears to be a useful tool in women with longer timelines for achieving pregnancy (87). For those women with a short term but not immediate desire for pregnancy, consideration should be given to pretreatment with metformin before prescribing CC for ovulation induction. This option may allow metformin to develop its full reproductive and metabolic efficacy since its onset of action is known to be gradual. In these cases, pretreatment of obese patients with metformin combined with lifestyle modification may result in weight loss, which reduces the likelihood of clomiphene resistance and the risk for gestational or obstetrical complications (87). Additionally, in those patients for whom pregnancy is a distant goal, metformin treatment, combined with lifestyle modification, is a reasonable option for ovulation induction, which may also alleviate the risk of multiparity (87).

Another scarcely explored area regards the role of metformin co-administration during gonadotrophin ovulation induction or IVF in women with PCOS. As highlighted by a recent meta-analysis (88), available evidence is inconclusive, but existing data suggest that metformin co-administration may reduce the risk of ovarian hyperstimulation syndrome (OHSS) (88).

However, this meta-analysis was conducted earlier than the publication of the largest RCT on the effects of metformin co-treatment in women with PCOS undergoing IVF. This study reported that a 28-day course of metformin during the IVF cycle improves the pregnancy outcome and reduces the risk of OHSS despite the fact that it failed to improve the response to stimulation and the fertilization rate (89). The parallel reduction of serum levels of vascular endothelial growth factor (VEGF) in the 'metformin co-treatment arm' has been associated with lower OHSS risk (89). These 
findings are compatible with the concept that VEGF through the stimulation of ovarian angiogenesis may be a key mediator of OHSS (90). The observed reduction of VEGF levels may significantly rely upon the insulinlowering effect of metformin since insulin stimulates VEGF production by cultured luteinized granulosa cells from women with and without PCOS (91).

Metformin use during pregnancy: gestational complications and impact on fetus In addition to difficulty in conceiving, women with PCOS are at increased risk for early miscarriage. Other gestational complications, mainly gestational diabetes (GD) and preeclampsia, as well as neonatal complications, namely preterm birth and perinatal morbidity and mortality, are also more prevalent in these women (92).

IR and hyperinsulinemia may contribute to the propensity of PCOS women to the above adverse events. In particular, potential mechanisms for the association of IR with increased early miscarriage rate in PCOS are the increase of PAI-1 and the reduction of glycodelin levels $(93,94)$. Increased PAI-1 levels during pregnancy may promote thrombosis, thus leading to placental insufficiency (95). In addition, glycodelin is a glycoprotein produced by endometrial glands during the luteal phase, which facilitates embryo implantation (96). Hence, decreased glycodelin levels may play a part in the pathogenesis of PCOS-related early pregnancy loss (96).

IR is also pathophysiologically linked with GD and preeclampsia, both of which impose a major risk for maternal and neonatal complications. Increased placental IR directly impairs nutrient supply to the fetus and leads to fetal growth restriction $(97,98)$. Hence, insulin-resistant women with PCOS appear to be predisposed to high-risk pregnancies.

Considering the adverse impact of IR on the physiology of pregnancy, continued metformin treatment after conception in women with PCOS may be beneficial. Metformin therapy throughout pregnancy may reduce the risk of early miscarriage after either spontaneous or assisted conception and the incidence of GD (99-103), while it may ameliorate neonatal outcomes (102, 104, 105).

However, the aforementioned data have been derived from small studies, limited further by their retrospective design $(100,102)$, the lack of a prospectively studied control group (106), and the lack of adjustment for major confounders, such as preconception weight loss (112). Adding another caveat, some studies (99, $102,107,108)$ have compared posttreatment outcome with pretreatment outcome in the same patients, which has been criticized as statistically invalid (109). Therefore, available evidence is still insufficient to establish the benefit of metformin use during pregnancy.

Although alleviation of IR is the hallmark of metformin's action, the specific mediators through which insulin sensitization may improve pregnancy outcomes remain under investigation. More specifically, in nonpregnant women with PCOS metformin was shown to increase serum glycodelin levels, which are reduced in hyperinsulinemic patients (110). This effect if extrapolated to pregnant women with PCOS offers a potential mechanism for the reported beneficial effect of metformin on pregnancy outcomes in PCOS women. Another potential mechanism is the metformin-induced reduction of PAI-1 levels which are increased in PCOS pregnancies with a high miscarriage risk $(99,111)$.

Most recently, innovative animal studies have provided interesting insights into the potential mechanisms underlying the beneficial effects of metformin throughout pregnancy. In murine embryos exposed to insulinlike growth factor-1, at concentrations approximating those occurring in PCOS, metformin via AMPK activation improved insulin-stimulated glucose uptake and decreased apoptosis, while increasing implantation rates (112). Likewise, when supplemented during in vitro culture and maturation, metformin enhanced insulin action to facilitate the developmental competence of porcine oocytes and subsequent embryo development (113).

Overall, it is important to note that the beneficial role of metformin in pregnancy-related parameters may be accomplished through a continuum of effects which starts from preconception and lasts throughout pregnancy. In the preconception period, weight loss and attenuation of IR and androgen excess promoted by the combination of metformin treatment with diet may reduce the likelihood of GD in women with PCOS (108).

In addition to efficacy, metformin should also prove safe for the fetus in order to become an established pharmaceutical modality during pregnancy. In ex vivo model systems, metformin was shown to cross the human placenta $(114,115)$. In accordance with these findings, metformin has been detected in umbilical cord blood at levels equal to or higher than the ones in maternal venous blood (116-118). Thus, metformin could directly affect fetal physiology and embryonic development (119). Although available evidence suggests that metformin has no toxicity, there have been concerns regarding the potential impact of metformin in pregnancies complicated with impaired placental perfusion and fetal growth restriction. In such conditions, the fetus may rely on the development of peripheral IR to enhance survival, and an insulin modulator, such as metformin, may interfere with this adaptive mechanism (120).

To date, available clinical data on metformin's safety in human pregnancies are sparse. A metaanalysis of preliminary studies in diabetic women unselected for PCOS and nondiabetic women with PCOS was reassuring for the safety of metformin use in the first gestational trimester (121). Nevertheless, this meta-analysis addressed only major neonatal malformations. Other significant outcomes, such as the stillbirth, minor anomalies, and intrauterine growth 
retardation, were not addressed. Most importantly, the authors highlighted the need for long-term follow-up of children born to metformin-treated pregnancies. Subsequent to this meta-analysis, a retrospective study has examined a wider array of perinatal outcomes in metformin-treated and control pregnancies, matched for age and parity. Neonatal growth deficits, congenital defects, hypoglycemia, and neonatal unit admission were found to be either comparable between groups or less common in the metformin-treated group (122).

In conclusion, metformin treatment has been used in pregnant women with PCOS with favorable results. However, current data on safety and efficacy await confirmation by randomized controlled studies before metformin is recommended for widespread use in pregnant women with PCOS.

\section{Effects on metabolic abnormalities in PCOS}

The benefit of metformin treatment on cardiometabolic abnormalities associated with PCOS appears to rely on the reduction of glucose levels and the attenuation of IR. The still debatable role of metformin in weight reduction may also contribute to a more favorable cardiometabolic profile in women with PCOS. Overall, metformin should be used as an adjuvant to lifestyle modification but not as a substitute for it. When combined with lifestyle intervention, metformin may improve cardiometabolic aspects in an additive manner.

Disorders of glucose tolerance The salutary effect of metformin on peripheral IR has been confirmed in women with PCOS. Using the hyperinsulinemic-euglycemic clamp, Diamanti-Kandarakis et al. showed that metformin increases insulin-stimulated glucose disposal in normoglycemic women with the syndrome (123). Thus, in women with PCOS, metformin treatment may confer a dual protection against T2D, through glucose lowering and through peripheral insulin sensitization. Both effects are considered to contribute to sparing of pancreatic $\beta$-cell reserve. In RCTs, metformin was shown to significantly decrease the risk for progression to T2D in patients with IGT at baseline $(124,125)$.

However, it is unknown whether these results pertain to women with PCOS as well. To date, no RCT has addressed the effect of metformin on the natural course of T2D in patients with PCOS. Encouraging data were derived from an uncontrolled retrospective study in a small number of PCOS women treated with metformin for an average of 43 months. In this study, none of the participants developed T2D, even though a substantial portion $(22 \%)$ had IGT at baseline. Additionally, the annual conversion rate from normal glucose tolerance to IGT was only $1.4 \%$ as compared with $16-19 \%$ reported in the literature for women with PCOS (126).

The baseline status of insulin sensitivity and glycemia may determine the natural course of diabetes in PCOS women treated with metformin. In a prospective, observational study among a large PCOS cohort, the efficacy of intervention with metformin plus diet in averting T2D was shown to depend on pretreatment glucose levels and homeostatic assessment model for insulin resistance (HOMA-IR) and the degree of posttreatment reduction of HOMA-IR (127). However, without a double-blind, placebo-controlled design, the study results are liable to confounders.

Body weight and fat distribution Obesity is a common phenotype in women with PCOS, which aggravates both the metabolic and the reproductive components of the syndrome. Abnormal central regulation of appetite involving insulin, leptin, ghrelin, and neuropeptide Y (NPY) may contribute to obesogenic dietary habits in these subjects $(128,129)$. In particular, obese PCOS women displayed a blunted counter regulatory response of NPY to oral glucose and to ghrelin; hyperinsulinemia has been implicated in impairing NPY secretion in these women $(129,130)$.

In view of the detrimental impact of obesity on multiple aspects of PCOS, weight loss and ideal weight maintenance are the major therapeutic goals in these patients. The role of metformin in promoting weight loss remains disputable. In relevant studies among adolescents and adults unselected for PCOS, metformin treatment has yielded promising results. However, these studies have included only small numbers of participants (131).

Specific data regarding the weight-reducing effect of metformin in women with PCOS are also limited in amount. The Cochrane Library review of RCTs addressing the effectiveness of metformin in improving features of PCOS could not confirm any weight-reducing effect (74). Two subsequent studies have included prospective cohorts of women with PCOS randomized to different metformin doses. Both have shown a dosedependent capacity of this drug to promote weight loss, with daily doses as high as $2500-2550 \mathrm{mg}$ being more advantageous in this aspect $(132,133)$. However, none of these studies included a placebo arm.

More recently, in a randomized, controlled, doubleblinded setup, metformin was shown to reduce weight in obese women with PCOS as compared to an observed weight gain in placebo-treated patients (Table 1). Strengths of this study were the number of participants and the crossover design, while limitations were the high dropout rate and the lack of consideration for possible lifestyle changes during the study period (134).

Even if metformin actually contributes to weight loss, the potential mechanisms mediating this effect remain unclear. In view of the association of hyperinsulinemia with impaired NPY-ghrelin relationship in PCOS, a recent study has investigated the impact of metformin on central hormonal appetite regulators (129). This study has demonstrated that metformin treatment tends to restore the secretory capacity of NPY in obese women with PCOS. These findings offer a potential 
mechanism for the weight-reducing effect of metformin through normalization of appetite regulation in PCOS women (129).

Considering that central fat accumulation is closely relevant to cardiometabolic outcomes, the specific effect of metformin on central adiposity deserves discussion. In that context, a cautionary note should be raised about the difficulty in the clinical assessment of fat distribution. Available studies have used different measures for central fat mass, including clinical markers, such as waist-to-hip ratio (WHR) and waist circumference (WC), or imaging techniques. More specifically, the Cochrane review found no evidence for an effect of metformin on WHR in women with PCOS (74). Concordant findings have been provided by a recent randomized, double-blind, and placebocontrolled study which has used computed tomography to assess visceral fat mass as a primary outcome measure (135). Obese women with PCOS were treated with either metformin ( $500 \mathrm{mg}$ thrice daily) or placebo without lifestyle modification. Nonetheless, the duration of pharmaceutical intervention was only 3 months, which may not allow metformin to reach its maximal efficacy. Additionally, this study lacked the sensitivity to detect modest fat mass reductions (135).

However, there is growing evidence that metformin may enhance the degree of visceral fat loss when combined with lifestyle modification. In three consecutive publications by an Italian group of investigators, metformin ( $850 \mathrm{mg}$ twice daily) in combination with hypocaloric diet, as compared with hypocaloric diet alone, led to significant reductions in visceral fat mass (136-138). Similarly, an RCT (139) of metformin (850 mg twice daily) plus lifestyle modification over 6 months in obese women with PCOS found a significant reduction in WC compared with lifestyle changes alone. As with BMI reduction, the effect of metformin on central adiposity appears to be maximized at higher doses, up to $2500 \mathrm{mg}$ /day (132). Nevertheless, metformin treatment does not appear to significantly alter adipokine secretion in women with PCOS $(140,141)$.

Overall, the role of metformin in the reduction of body weight and central fat remains investigational until further research is conducted. For the time being, the combination of metformin with lifestyle modification, including calorie restriction and exercise, appears to facilitate weight loss and attenuate central adiposity. Higher doses of metformin may be required to achieve an optimal response to treatment.

Other cardiovascular risk factors and markers Metformin has been reported to ameliorate several classic components of the metabolic syndrome in women with PCOS. In a meta-analysis of RCTs conducted in these patients, metformin therapy resulted in significant decreases in systolic blood pressure (SBP) and in low density lipoprotein (LDL)-cholesterol levels (74). Subsequent RCTs in overweight and obese patients have also shown that metformin treatment, without any specific lifestyle modification, lowers SBP (142) and promotes a less atherogenic lipid profile $(12,133,141)$. Some investigators have reported lower total cholesterol and LDL-cholesterol levels $(12,133)$, while others have shown higher high density lipoprotein (HDL) levels following a 3-6-month treatment (141).

However, since no pharmaceutical agent can substitute for lifestyle modification, metformin should be considered as an adjunct to lifestyle changes. In women with PCOS, metformin co-administration may add to the metabolic benefit of calorie restriction (136). However, a recent placebo-controlled RCT in morbidly obese patients taking a standard hypocaloric diet reported failure of metformin to confer additive metabolic benefit (137). Extreme obesity and the minimal amount of weight lost may account for the persistence of metabolic abnormalities even in those women treated with the combination of metformin and lifestyle intervention (137).

The metabolic effects of metformin appear to rely primarily upon the improvement of insulin sensitivity in insulin-resistant patients with PCOS (3). Although in some studies lipid alterations were not accompanied by apparent changes in IR (135), surrogate indices such as HOMA-IR and QUICKI may have failed to detect subtle alterations in IR.

However, in lean patients, who are less insulin resistant than obese ones, the mechanism whereby metformin may modify cardiovascular risk factors is not apparent. Studies addressing the specific metabolic effects of metformin in lean women with PCOS are not abundant and not free of limitations. A prospective uncontrolled study (142) in a small sample of lean, normoinsulinemic PCOS women failed to show significant differences in lipid and homocysteine levels, carotid artery intima media thickness, and 24-h ambulatory blood pressure monitoring following 6-month metformin therapy. Similarly, a placebocontrolled RCT reported that nonobese patients are not benefited by metformin treatment in metabolic terms (134). The lack of pronounced disturbances at baseline may explain why metformin fails to achieve a detectable metabolic benefit.

In conjunction with the clustering of components of the metabolic syndrome, young women with PCOS display chronic inflammation and dysfibrinolysis as well as evidence of subclinical cardiovascular dysfunction. Metformin has been reported to reduce markers of inflammation (143, 144), and dysfibrinolysis (145). Metformin also improves functional and biochemical markers of endothelial reactivity as well as surrogate indices of coronary atherosclerosis. More specifically, a 6-month treatment was found to increase brachial artery flow-mediated dilatation in obese as well as lean women with PCOS (146-148). Metformin also decreases serum levels of ET-1, which is the most potent vasoconstrictor and is found at increased levels in 
women with PCOS over a wide BMI range (149). Additionally, coronary microvascular function and coronary flow reserve, assessed by transthoracic Doppler echocardiography, were significantly improved following 6-month metformin therapy in women with PCOS (150). These data bear significant implications since the above markers are considered sensitive predictors for cardiovascular disorders $(151,152)$.

Vascular actions of metformin appear to involve the attenuation of IR/hyperinsulinemia in women with PCOS $(147,148)$. Several investigators have emphasized the key role of IR in endothelial damage (153-155).

However, 6-month metformin treatment was shown to retain efficacy in ameliorating endothelial dysfunction in lean normoinsulinemic women with PCOS (153). This finding suggests that other mechanisms, apart from IR, contribute to the endothelial effects of this drug.

More specifically, serum androgen levels have been correlated with endothelial dysfunction in women with PCOS (156-158), and hence there may be a link between the reduction of testosterone levels and the posttreatment improvement of vascular function following metformin treatment. Accordingly, a recent study in women with PCOS suggested that metformin decreases serum levels of asymmetric dimethylarginine (ADMA) levels, an endogenous inhibitor of NOS, through concomitant effects on insulin action and androgen levels (159). In another study, metformin treatment led to a decrease in ADMA levels which could not be accounted for by metabolic changes, leaving room for androgens to play an instrumental role (160).

Another mechanism appears to be the reduction of circulating advanced glycated end products (AGEs), which are oxidative mediators of endothelial dysfunction. More specifically, a 6-month treatment with metformin $(1700 \mathrm{mg} /$ day $)$ was shown to reduce serum AGEs, without BMI changes, in women with PCOS (161). Since circulating AGEs levels are increased even in lean, normoglycemic women with PCOS (162), the AGE-lowering effect of metformin may have clinical relevance, independently of BMI.

Furthermore, metformin may directly affect endothelial function. Randomized, double-blind, placebocontrolled studies in type 2 diabetics and in nondiabetic women suggested a direct vasoactive effect of metformin, independent of its effects on insulin, weight, and inflammatory mediators $(163,164)$. As discussed above, metformin is able to stimulate intracellular AMPK and to phosphorylate the endothelial isoform of NOSs in human aortic endothelial cells $(64,165)$.

\section{Predictors of response to metformin}

Reflecting the clinical and pathophysiologic heterogeneity of PCOS, treatment with metformin can elicit variable results, ranging from no response to moderate or significant improvement. Arguably, phenotypes of PCOS with distinct endocrine and metabolic feautures may be differentially affected by metformin therapy. However, the determinants of response to metformin therapy in women with PCOS remain enigmatic (52).

Despite the lack of clear-cut evidence, clinical studies have attempted to identify predictors of response to metformin. Interestingly, favorable metabolic changes are often paralleled by reproductive improvement in treated patients. This observation is compatible with the fact that both the metabolic and the reproductive effects of metformin depend, to a large extent, on the alleviation of IR.

Baseline BMI emerges as the major predictor of the response to treatment in women with PCOS. Higher BMIs appear to be associated with suboptimal therapeutic results of metformin regarding metabolic as well as reproductive abnormalities. It is commonly experience that obese women, particularly those with morbid obesity, are refractory to metformin therapy $(139,166)$. Obesity counteracts the attenuation of IR induced by metformin. This adverse interaction compromises the overall therapeutic efficacy of the drug, including both metabolic and reproductive aspects $(82,136$, 167-172).

Most recently, a study among infertile, anovulatory women with PCOS has searched for the baseline predictors of pregnancy in PCOS patients who received metformin for ovulation induction. Baseline BMI was confirmed as a major predictor of both ovulation and pregnancy under metformin treatment. As expected, advanced age and longer duration of infertility had an adverse impact on pregnancy response under metformin. This study has also attempted to distinguish between the phenotype who may benefit from metformin therapy and the one who may respond better to CC therapy (173). Insulin-resistant PCOS patients with low BMI were reported to be more likely to respond to metformin, whereas CC treatment was more effective in less hyperandrogenic and more insulin-sensitive patients with low BMI.

However, previous studies did not confirm the predictive value of IR indices for ovulation induction by metformin $(167,169,174)$. This discrepancy may reside in the use of surrogate mathematical indices for the assessment of IR (175). Alternatively, the dissociation between the improvement of insulin sensitivity and the restoration of ovulation implicates other mechanisms, independent of insulin, in the reproductive response to metformin. For example, metformin may be able to directly affect ovarian steroidogenesis $(55,59)$. In addition, this drug could affect the central regulation of ovulation by modulating GnRH release through the activation of the hypothalamic AMPK (176).

The degree of androgen excess may be another determinant of the reproductive efficacy of metformin. 
In studies evaluating the posttreatment ovulation rate $(167,172,177)$, responders to metformin were less hyperandrogenic than nonresponders.

The role of the genotype is also currently explored. In a prospective randomized trial, a specific polymorphism in STK11 (also known as LKB1), a kinase gene expressed in liver and implicated in metformin's action, was associated with ovulatory response to treatment with metformin (172).

\section{The ancillary role of metformin in the treatment of skin manifestations in PCOS}

Dermatological manifestations in women with PCOS are most often the result of androgen excess acting upon the skin. Hirsutism is the major skin manifestation of androgen excess in PCOS. Other clinical signs of hyperandrogenism are acne and androgenic alopecia; however, their association with biochemical hyperandrogenemia in PCOS has not been definitely identified (178).

The utility of metformin in the symptomatic management of hirsutism in women with PCOS remains inadequately studied and is still surrounded by controversy (136, 177, 179-182). Only few studies have assessed hirsutism as a primary endpoint. More specifically, a double-blind RCT in a small PCOS population favored metformin over placebo, while another study reported superiority of metformin over an established treatment for hirsutism, the combined ethinyl $E_{2}$ and cyproterone acetate pill. Of note, these two studies have attempted to cross-check the Ferriman-Gallwey (F-G) hirsutism score using other methods, such as the patient self-evaluation score or more objective measures, such as the plucked hair length $(182,183)$.

A recent meta-analysis has included all RCTs, which measured hirsutism as an outcome, in hirsute women with PCOS receiving treatment with metformin or thiazolinediones, alone or in combination with oral contraceptive pills (OCPs) or antiandrogens, or with placebo or active control (OCPs or antiandrogens). A significant advantage of metformin over OCPs and antiandrogens is the fact that it can be prescribed in women planning pregnancy. Although the aforementioned meta-analysis has ascribed minimal efficacy to metformin in the treatment of hirsutism, it should be noted that available evidence was criticized for impreciseness, inconsistency, and poor methodological quality (184). In the majority of studies, the assessment of hirsutism was based on the $\mathrm{F}-\mathrm{G}$ scale, which is inherently liable to subjectivity and has acknowledged limitations (185). Therefore, any conclusion on the efficacy of metformin seems premature.

Another meta-analysis of four RCTs specifically comparing metformin with OCPs concluded that the limited evidence to date does not show any difference in effect between these two pharmaceutical options on hirsutism or acne (186).

Since the completion of the above meta-analyses, a couple of pertinent trials have been published. Overall, in the pharmaceutical management of hirsutism metformin appears to be inferior to antiandrogens (flutamide or the OCP-containing cyproterone acetate) $(138,187)$, while it has efficacy comparable with that of OCPs (188).

\section{Adverse effects}

The most common adverse effects of metformin relate to the gastrointestinal tract, including watery diarrhea, nausea, abdominal pain, abdominal bloating, flatulence, dyspepsia, metallic taste, and anorexia. These effects occur in 10-50\% of patients receiving metformin therapy, but resolve within a few days to weeks after the initiation of therapy. Their severity can be lessened by employing a gradual titration schedule, taking metformin with food, and/or temporarily lowering the dosage. Metformin should be initiated at a dose of $500 \mathrm{mg}$ once daily with the largest meal, and the dose should be then increased weekly in $500 \mathrm{mg}$ steps if required (maximum 2500-2550 mg/day in three divided doses with meals). If nausea or diarrhea occurs at a given dose, that dose is either maintained or decreased by $500 \mathrm{mg} /$ day for $2-4$ weeks until the symptoms abate. When diarrhea, attributed to an alteration in the absorption of bile salts, does not resolve, discontinuation of the medication may be necessary. In general, $<5 \%$ of patients are unable to tolerate metformin as a result of prolonged adverse effects (52).

Metformin therapy can cause malabsorption of vitamin B12 in the distal ileum in 10-30\% of patients. Proposed mechanisms by which metformin affects vitamin B12 absorption involve altered small bowel motility, bacterial overgrowth, and direct effects on mucosal cell and intracellular handling of calcium. In patients treated with metformin, an increased risk of vitamin B12 deficiency has been associated with increasing patient age, current dose, and duration of metformin use (189). The presenting symptoms of vitamin B12 deficiency may be indistinguishable from those of peripheral neuropathy, while hematological repercussions may also occur. Nevertheless, only a small number of metformin-associated megaloblastic anemias have been reported in the literature (190). Vitamin B12 deficiency may also evoke hyperhomocysteinemia, which is linked with adverse cardiovascular effects. Therefore, during metformin therapy plasma levels of vitamin B12 should be measured, and patients should be monitored for clinical signs and symptoms of vitamin B12 deficiency (52).

Lactic acidosis is a rare, potentially fatal metabolic condition described as a biguanide class effect. Lactic acidosis can occur whenever substantial tissue hypoperfusion and hypoxia exist. However, the two 
biguanides, metformin and phenformin, influence lactate metabolism in different ways. Metformin binds with a much lower affinity than phenformin to mitochondrial membranes and does not adversely affect mitochondrial lactate oxidation, unless plasma concentrations of metformin are excessive (190).

Lactic acidosis has been rarely reported with the use of metformin, mostly in patients with contraindications to the drug or in cases of intoxication after drug overdosage. Contraindications for metformin include renal dysfunction (a serum creatinine level $>1.4 \mathrm{mg} / \mathrm{dl}$ ), hepatic dysfunction, severe congestive heart failure, or a history of alcohol abuse.

However, in the absence of contraindications, the increased risk of lactic acidosis is either zero or negligible. More specifically, in a large study (the comparative outcomes study of metformin intervention versus conventional approach (COSMIC)) (191), there were no cases of lactic acidosis among 7227 diabetic patients who received 1-year treatment with metformin. Even before the publication of this trial, Salpeter et al. (192) had reviewed published reports of controlled trials involving metformin and found no cases of lactic acidosis in 36000 patient-years of exposure.

\section{Conclusions}

Metformin has been traditionally known for its metabolic effects on the liver. The landscape of the multifaceted actions of metformin evolves to broaden the therapeutic implications of this old drug for patients with PCOS. Additional target tissues of metformin are the skeletal muscle and the adipose tissue. In view of its favorable metabolic actions, metformin is a useful adjuvant to lifestyle modification in overweight and obese patients with PCOS with features of metabolic syndrome or IGT. In women with PCOS and T2D, metformin is an appropriate first-line medical therapy. Most recently, the spectrum of metformin's targets has been expanded to include the endothelium and the ovary. The direct endothelial actions of metformin appear to be of benefit in states characterized by endothelial dysfunction, like in PCOS. Furthermore, the putative direct ovarian actions of metformin may contribute to counterbalancing the intrinsic defect of ovarian steroidogenesis and some components of ovarian dysfunction in PCOS. Molecular studies have explored the tissue-specific mechanisms of metformin's actions. AMPK, a serine-threonine kinase that functions as an intracellular energy sensor, has been involved in the molecular mechanisms of metformin's actions in the liver, the muscle, the endothelium, and the ovary. The use of metformin in pregnant women with PCOS comprises another scarcely explored, but promising area of research. During pregnancy, the effects of metformin merit investigation not only in relation to the mother but also in relation to the fetus since metformin crosses the human placenta.

Even if many of these actions are individually modest, they seem to be collectively sufficient to confer therapeutic benefits not only in cardiometabolic aspects but also in reproductive aspects associated with insulinresistant and proinflammatory states, such as PCOS. The 50 years of its clinical use pose no major safety issues and the risk of serious adverse events attributable to metformin appears to be low provided that contraindications are considered. The evolving landscape of the multifaceted actions of metformin may rejuvenate the therapeutic applications of this old drug in general and specifically in the setting of PCOS.

\section{Declaration of interest}

The authors of this manuscript have no conflict of interest and no financial interest that could be perceived as prejudicing the impartiality of the research reported.

\section{Funding}

There is no funding of this work and this research did not receive any specific grant from any funding agency in the public, commercial, or not-for-profit sector.

\section{References}

1 Diamanti-Kandarakis E, Kouli CR, Bergiele AT, Filandra FA, Tsianateli TC, Spina GG, Zapanti ED \& Bartzis MI. A survey of the polycystic ovary syndrome in the Greek island of Lesbos: hormonal and metabolic profile. Journal of Clinical Endocrinology and Metabolism 199984 4006-4011.

2 Diamanti-Kandarakis E. Polycystic ovarian syndrome: pathophysiology, molecular aspects and clinical implications. Expert Reviews in Molecular Medicine 200810 e3 (Review).

3 Palomba S, Falbo A, Zullo F \& Orio F Jr. Evidence-based and potential benefits of metformin in the polycystic ovary syndrome: a comprehensive review. Endocrine Reviews 200930 1-50.

4 Yuan L, Ziegler R \& Hamann A. Metformin modulates insulin post-receptor signaling transduction in chronically insulintreated Hep G2 cells. Acta Pharmacologica Sinica 200324 55-60.

5 Ashokkumar N \& Pari L. Effect of N-benzoyl-D-phenylalanine and metformin on carbohydrate metabolic enzymes in neonatal streptozotocin diabetic rats. Clinica Chimica Acta 2005351 $105-113$.

6 Gunton JE, Delhanty PJ, Takahashi S \& Baxter RC. Metformin rapidly increases insulin receptor activation in human liver and signals preferentially through insulin-receptor substrate- 2 . Journal of Clinical Endocrinology and Metabolism $2003 \mathbf{8 8}$ 1323-1332.

7 Cheng JT, Huang CC, Liu IM, Tzeng TF \& Chang CJ. Novel mechanism for plasma glucose-lowering action of metformin in streptozotocin-induced diabetic rats. Diabetes 200655 819-825.

8 Mithieux G, Guignot L, Bordet JC \& Wiernsperger N. Intrahepatic mechanisms underlying the effect of metformin in decreasing basal glucose production in rats fed a high-fat diet. Diabetes 2002 51 139-143.

9 Lutz T, Estermann A, Haag S \& Scharrer E. Depolarization of the liver cell membrane by metformin. Biochimica et Biophysica Acta-Biomembranes $2001 \mathbf{1 5 1 3} 176-184$. 
10 Guigas B, Detaille D, Chauvin C, Batandier C, De Oliveira F, Fontaine E \& Leverve X. Metformin inhibits mitochondrial permeability transition and cell death: a pharmacological in vitro study. Biochemical Journal 2004382 877-884.

11 Fulgencio JP, Kohl C, Girard J \& Pégorier JP. Effect of metformin on fatty acid and glucose metabolism in freshly isolated hepatocytes and on specific gene expression in cultured hepatocytes. Biochemical Pharmacology 200162 439-446.

12 Iozzo P, Hallsten K, Oikonen V, Virtanen KA, Parkkola R, Kemppainen J, Solin O, Lonnqvist F, Ferrannini E, Knuuti J \& Nuutila P. Effects of metformin and rosiglitazone monotherapy on insulin-mediated hepatic glucose uptake and their relation to visceral fat in type 2 diabetes. Diabetes Care 200326 2069-2074

13 Zang M, Zuccollo A, Hou X, Nagata D, Walsh K, Herscovitz H, Brecher P, Ruderman NB \& Cohen RA. AMP-activated protein kinase is required for the lipid-lowering effect of metformin in insulin resistant human HepG2 cells. Journal of Biological Chemistry 2004279 47898-47905.

14 Cleasby ME, Dzamko N, Hegarty BD, Cooney GJ, Kraegen EW \& Ye JM. Metformin prevents the development of acute lipidinduced insulin resistance in the rat through altered hepatic signaling mechanisms. Diabetes 200453 3258-3266.

15 Viollet B, Foretz M, Guigas B, Horman S, Dentin R, Bertrand L, Hue L \& Andreelli F. Activation of AMP-activated protein kinase in the liver: a new strategy for the management of metabolic hepatic disorders. Journal of Physiology 2006 574 41-53.

16 Fujii N, Jessen N \& Goodyear LJ. AMP-activated protein kinase and the regulation of glucose transport. American Journal of Physiology. Endocrinology and Metabolism 2006291 E867-E877.

17 Kim Y, Park K-G, Lee Y-S, Park YY, Kim DK, Nedumaran B, Jang WG, Cho WJ, Ha J, Lee IK, Lee CH \& Choi HS. Metformin inhibits hepatic gluconeogenesis through AMP-activated protein kinase-dependent regulation of the orphan nuclear receptor SHP. Diabetes 200857 306-314.

18 Shaw RJ, Lamia KA, Vasquez D, Koo SH, Bardeesy N, Depinho RA, Montminy M \& Cantley LC. The kinase LKB1 mediates glucose homeostasis in liver and therapeutic effects of metformin. Science $20053101642-1646$.

19 Koo SH, Flechner L, Qi L, Zhang X, Screaton RA, Jeffries S, Hedrick S, Xu W, Boussouar F, Brindle P, Takemori H \& Montminy M. The CREB coactivator TORC2 is a key regulator of fasting glucose metabolism. Nature 2005 437 1109-1111.

20 Kumar N \& Dey CS. Metformin enhances insulin signalling in insulin-dependent and independent pathways in insulin resistant muscle cells. British Journal of Pharmacology 2002137 329-336.

21 Kim YB, Ciaraldi TP, Kong A, Kim D, Chu N, Mohideen P, Mudaliar S, Henry RR \& Kahn BB. Troglitazone but not metformin restores insulin-stimulated phosphoinositide 3-kinase activity and increases p110beta protein levels in skeletal muscle of type 2 diabetic subjects. Diabetes $200251443-448$.

22 Al-Khalili L, Forsgren M, Kannisto K, Zierath JR, Lönnqvist F \& Krook A. Enhanced insulin-stimulated glycogen synthesis in response to insulin, metformin or rosiglitazone is associated with increased mRNA expression of GLUT4 and peroxisomal proliferator activator receptor gamma co-activator 1 . Diabetologia 200548 1173-1179.

23 Driscoll SD, Meininger GE, Ljungquist K, Hadigan C, Torriani M, Klibanski A, Frontera WR \& Grinspoon S. Differential effects of metformin and exercise on muscle adiposity and metabolic indices in human immunodeficiency virus-infected patients. Journal of Clinical Endocrinology and Metabolism $2004 \mathbf{8 9}$ 2171-2178.

24 Mathieu-Costello O, Kong A, Ciaraldi TP, Cui L, Ju Y, Chu N, Kim D, Mudaliar S \& Henry RR. Regulation of skeletal muscle morphology in type 2 diabetic subjects by troglitazone and metformin: relationship to glucose disposal. Metabolism 200352 540-546.

25 Collier C, Bruce C, Smith A, Lopaschuk G \& Dyck D. Metformin counters the insulin-induced suppression of fatty acid oxidation and stimulation of triacylglycerol storage in rodent skeletal muscle. American Journal of Physiology. Endocrinology and Metabolism 2006291 E182-E189.

26 Smith AC, Mullen KL, Junkin KA, Nickerson J, Chabowski A, Bonen A \& Dyck DJ. Metformin and exercise reduce muscle FAT/CD36 and lipid accumulation and blunt the progression of high-fat diet-induced hyperglycemia. American Journal of Physiology. Endocrinology and Metabolism 2007293 E172-E181.

27 Natali A \& Ferrannini E. Effects of metformin and thiazolidinediones on suppression of hepatic glucose production andstimulation of glucose uptake in type 2 diabetes: a systematic review. Diabetologia 200649 434-441.

28 Musi N, Hirshman M, Nygren J, Svanfeldt M, Bavenholm P, Rooyackers O, Zhou G, Williamson JM, Ljungvist O, Efendic S, Moller DE, Thorell A \& Goodyear LJ. Metformin increases AMPactivated protein kinase activity in skeletal muscle of subjects with type 2 diabetes. Diabetes $2002512074-2081$.

29 Zou M-H \& Wu Y. AMP-activated protein kinase activation as a strategy for protecting vascular endothelial function. Clinical and Experimental Pharmacology and Physiology 200835 535-545.

30 Luna V, Casauban L \& Sajan M. Metformin improves atypical protein kinase $\mathrm{C}$ activation by insulin and phosphatidylinositol3,4,5-( $\left(\mathrm{PO}_{4}\right)_{3}$ in muscle of diabetic subjects. Diabetologia 200649 $375-382$.

31 Lenhard JM, Kliewer SA. Paulik MA. Plunket KD, Lehmann JM \& Weiel JE. Effects of troglitazone and metformin on glucose and lipid metabolism: alterations of two distinct molecular pathways. Biochemical Pharmacology 199754 801-808.

32 Ciaraldi TP, Kong AP, Chu NV, Kim DD, Baxi SS, Loviscach M, Plodkowski R, Reitz R, Caulfield M, Mudaliar S \& Henry RR. Regulation of glucose transport and insulin signaling by troglitazone or metformin in adipose tissue of type 2 diabetic subjects. Diabetes 200251 30-36.

33 Virtanen KA, Lonnroth P, Parkkola R, Peltoniemi P, Asola M, Viljanen T, Tolvanen T, Knuuti J, Rönnemaa T, Huupponen R \& Nuutila P. Glucose uptake and perfusion in subcutaneous and visceral adipose tissue during insulin stimulation in nonobese and obese humans. Journal of Clinical Endocrinology and Metabolism 200287 3902-3910.

34 Ren T, He J, Jiang H, Zu L, Pu S, Guo X \& Xu G. Metformin reduces lipolysis in primary rat adipocytes stimulated by tumor necrosis factor- $\alpha$ or isoproterenol. Journal of Molecular Endocrinology 2006 37 175-183.

35 Alexandre KB, Smit AM, Gray IP \& Crowther NJ. Metformin inhibits intracellular lipid accumulation in the murine preadipocyte cell line, 3T3-L1. Diabetes, Obesity and Metabolism 2008 10 688-690.

36 Ranganathan G, Unal R, Pokrovskaya I, Yao-Borengasser A, Phanavanh B, Lecka-Czernik B, Rasouli N \& Kern PA. The lipogenic enzymes DGAT1, FAS, and LPL in adipose tissue: effects of obesity, insulin resistance, and TZD treatment. Journal of Lipid Research $2006472444-2450$.

37 Després JP. Potential contribution of metformin to the management of cardiovascular disease risk in patients with abdominal obesity, the metabolic syndrome and type 2 diabetes. Diabetes and Metabolism 200329 6S53-6S61.

38 Ibáñez L, López-Bermejo A, Díaz M, Marcos MV \& de Zegher F. Metformin treatment for four years to reduce total and visceral fat in low birth weight girls with precocious pubarche. Journal of Clinical Endocrinology and Metabolism 200893 1841-1845.

39 Rasouli N, Raue U, Miles LM, Lu T, Di Gregorio GB, Elbein SC \& Kern PA. Pioglitazone improves insulin sensitivity through reduction in muscle lipid and redistribution of lipid into adipose tissue. American Journal of Physiology. Endocrinology and Metabolism 2005288 E930-E934.

40 Seufert J, Lübben G, Dietrich K \& Bates PC. A comparison of the effects of thiazolidinediones and metformin on metabolic control in patients with type 2 diabetes mellitus. Clinical Therapeutics 200426 805-818.

41 Fujimoto WY, Jablonski KA, Bray GA, Kriska A, BarrettConnor E, Haffner S, Hanson R, Hill JO, Hubbard V, Stamm E, 
Pi-Sunyer FX \& and for the Diabetes Prevention Program Research Group. Body size and shape changes and the risk of diabetes in the Diabetes Prevention Program. Diabetes 200756 1680-1685.

42 Klein J, Westphal S, Kraus D, Meier B, Perwitz N, Ott V, Fasshauer M \& Klein HH. Metformin inhibits leptin secretion via a mitogen-activated protein kinase signalling pathway in brown adipocytes. Journal of Endocrinology 2004183 299-307.

43 Huypens P, Quartier E, Pipeleers D \& Van de Casteele M. Metformin reduces adiponectin protein expression and release in 3T3-L1 adipocytes involving activation of AMP activated protein kinase. European Journal of Pharmacology $2005 \mathbf{5 1 8}$ 90-95.

44 Kanda Y, Matsuda M, Tawaramoto K, Kawasaki F, Hashiramoto M, Matsuki M \& Kaku K. Effects of sulfonylurea drugs on adiponectin production from 3T3-L1 adipocytes: implication of different mechanism from pioglitazone. Diabetes Research and Clinical Practice 200881 13-18.

45 Fujita H, Fujishima H, Koshimura J, Hosoba M, Yoshioka N, Shimotomai T, Morii T, Narita T, Kakei M \& Ito S. Effects of antidiabetic treatment with metformin and insulin on serum and adipose tissue adiponectin levels in $\mathrm{db} / \mathrm{db}$ mice. Endocrine Journal 200552 427-433.

46 Tiikkainen M, Häkkinen AM, Korsheninnikova E, Nyman T, Mäkimattila S \& Yki-Järvinen $\mathrm{H}$. Effects of rosiglitazone and metformin on liver fat content, hepatic insulin resistance, insulin clearance, and gene expression in adipose tissue in patients with type 2 diabetes. Diabetes 200453 2169-2176.

47 Phillips SA, Ciaraldi TP, Kong AP, Bandukwala R, Aroda V, Carter L, Baxi S, Mudaliar SR \& Henry RR. Modulation of circulating and adipose tissue adiponectin levels by antidiabetic therapy. Diabetes 200352 667-674.

48 Varma V, Yao-Borengasser A, Rasouli N, Bodles AM, Phanavanh B, Lee MJ, Starks T, Kern LM, Spencer HJ III, McGehee RE Jr, Fried SK \& Kern PA. Human visfatin expression: relationship to insulin sensitivity, intramyocellular lipids, and inflammation. Journal of Clinical Endocrinology and Metabolism 200792 666-672.

49 Daval M, Foufelle F \& Ferre P. Functions of AMP-activated protein kinase in adipose tissue. Journal of Physiology 2006 574 55-62.

50 Christ-Crain M, Kola B, Lolli F, Fekete C, Seboek D, Wittmann G, Feltrin D, Igreja SC, Ajodha S, Harvey-White J, Kunos G, Müller B, Pralong F, Aubert G, Arnaldi G, Giacchetti G, Boscaro M, Grossman AB \& Korbonits M. AMP-activated protein kinase mediates glucocorticoid-induced metabolic changes: a novel mechanism in Cushing's syndrome. FASEB Journal 200822 $1672-1683$.

51 Ciaraldi TP, Oh DK, Christiansen L, Nikoulina SE, Kong APS, Baxi S, Mudaliar S \& Henry RR. Tissue-specific expression and regulation of GSK-3 in human skeletal muscle and adipose tissue. American Journal of Physiology. Endocrinology and Metabolism 2006291 E891-E898.

52 Nestler JE. Metformin for the treatment of the polycystic ovary syndrome. New England Journal of Medicine $20083 \mathbf{5 8} 47-54$.

53 Nestler JE \& Jakubowicz DJ. Decreases in ovarian cytochrome P450c17 alpha activity and serum free testosterone after reduction of insulin secretion in polycystic ovary syndrome. New England Journal of Medicine 1996335 617-623.

54 Diamanti-Kandarakis E \& Papavasiliou A. Molecular mechanisms of insulin resistance in polycystic ovary syndrome. Trends in Molecular Medicine 200612 324-332.

55 Attia GR, Rainey WE \& Carr BR. Metformin directly inhibits androgen production in human thecal cells. Fertility and Sterility 200176 517-524.

56 Tosca L, Solnais P, Ferre P, Foufelle F \& Dupont J. Metformininduced stimulation of adenosine $5^{\prime}$ monophosphate-activated protein kinase (PRKA) impairs progesterone secretion in rat granulosa cells. Biology of Reproduction 200675 342-351.

57 Nestler JE \& Jakubowicz DJ. Lean women with polycystic ovary syndrome respond to insulin reduction with decreases in ovarian P450c17 alpha activity and serum androgens. Journal of Clinical Endocrinology and Metabolism 199782 4075-4079.
58 La Marca A, Morgante G, Palumbo M, Cianci A, Petraglia F \& De Leo V. Insulin-lowering treatment reduces aromatase activity in response to follicle-stimulating hormone in women with polycystic ovary syndrome. Fertility and Sterility $2002 \mathbf{7 8}$ 1234-1239.

59 Mansfield R, Galea R, Brincat M, Hole D \& Mason H. Metformin has direct effects on human ovarian steroidogenesis. Fertility and Sterility 200379 956-962.

60 Arlt W, Auchus RJ \& Miller WL. Thiazolidinediones but not metformin directly inhibit the steroidogenic enzymes P450c17 and 3ß-hydroxysteroid dehydrogenase. Journal of Biological Chemistry 2001276 16767-16771.

61 Elia E, Sander V, Luchetti CG, Solano ME, Di Girolamo G, Gonzalez C \& Motta AB. The mechanisms involved in the action of metformin in regulating ovarian function in hyperandrogenized mice. Molecular Human Reproduction 200612 475-481.

62 Tosca L, Froment P, Solnais P, Ferré P, Foufelle F \& Dupont J. Adenosine $5^{\prime}$-monophosphate-activated protein kinase regulates progesterone secretion in rat granulosa cells. Endocrinology 2005 $1464500-4513$.

63 Muniyappa R, Montagnani M, Kon Koh K \& Quon M. Cardiovascular actions of insulin. Endocrine Reviews 200728 463-491.

64 Davis BJ, Xie Z, Viollet B \& Zou MH. Activation of the AMPactivated kinase by antidiabetes drug metformin stimulates nitric oxide synthesis in vivo by promoting the association of heat shock protein 90 and endothelial nitric oxide synthase. Diabetes 2006 55 496-505.

65 Detaille D, Guigas B, Chauvin C, Batandier C, Fontaine E, Wiernsperger N \& Leverve X. Metformin prevents high-glucoseinduced endothelial cell death through a mitochondrial permeability transition-dependent process. Diabetes $2005 \mathbf{5 4}$ 2179-2187.

66 Hattori Y, Suzuki K, Hattori S \& Kasai K. Metformin inhibits cytokine-induced nuclear factor kappaB activation via AMPactivated protein kinase activation in vascular endothelial cells. Hypertension 200647 1183-1188.

67 Huang NL, Chiang SH, Hsueh CH, Liang YJ, Chen YJ \& Lai LP. Metformin inhibits TNF-alpha-induced IkappaB kinase phosphorylation, IkappaB-alpha degradation and IL-6 production in endothelial cells through PI3K-dependent AMPK phosphorylation. International Journal of Cardiology 2009134 169-175.

68 McCarty MF. AMPK activation as a strategy for reversing the endothelial lipotoxicity underlying the increased vascular risk associated with insulin resistance syndrome. Medical Hypotheses 200564 1211-1215.

69 Xie Z, Dong Y, Scholz R, Neumann D \& Zou MH. Phosphorylation of LKB1 at serine 428 by protein kinase C-zeta is required for metformin-enhanced activation of the AMP-activated protein kinase in endothelial cells. Circulation 2008117 952-962.

70 Zou MH, Kirkpatrick SS, Davis BJ, Nelson JS, Wiles WG IV, Schlattner U, Neumann D, Brownlee M, Freeman MB \& Goldman MH. Activation of the AMP-activated protein kinase by the anti-diabetic drug metformin in vivo. Role of mitochondrial reactive nitrogen species. Journal of Biological Chemistry 2004 279 43940-43951.

71 Velazquez EM, Mendoza S, Hamer T, Sosa F \& Glueck CJ. Metformin therapy in polycystic ovary syndrome reduces hyperinsulinemia, insulin resistance, hyperandrogenemia, and systolic blood pressure, while facilitating normal menses and pregnancy. Metabolism 199443 647-654.

72 Diamanti-Kandarakis E. Insulin sensitizers targeting metabolic and reproductive consequences in polycystic ovary syndrome. In Polycystic Ovary Syndrome Current Controversies, From the Ovary to the Pancreas, Contemporary Endocrinology, ch. 13, pp 197-215. Eds Andrea Dunaif, R Jeffrey Chang, Stephen Franks \& Richard S Legro. Humana Press, 2008.

73 Practice Committee of the American Society for Reproductive Medicine. Use of insulin sensitizing agents in the treatment of polycystic ovary syndrome. Fertility and Sterility $2004 \mathbf{8 2}$ S181-S183. 
74 Lord JM, Flight IH \& Norman RJ. Metformin in polycystic ovary syndrome: systematic review and meta-analysis. BMJ $2003 \mathbf{3 2 7}$ 951-953.

75 Costello MF \& Eden JA. A systematic review of the reproductive system effects of metformin in patients with polycystic ovary syndrome. Fertility and Sterility 2003 79 1-13.

76 Cheang KI \& Nestler JE. Should insulin-sensitizing drugs be used in the treatment of polycystic ovary syndrome? Reproductive Biomedicine Online 20048 440-447.

77 De Leo V, La Marca A \& Petraglia F. Insulin-lowering agents in the management of polycystic ovary syndrome. Endocrine Reviews 200324 633-667.

78 Palomba S, Orio F Jr, Falbo A, Russo T, Tolino A \& Zullo F. Clomiphene citrate versus metformin as first-line approach for the treatment of anovulation in infertile patients with polycystic ovary syndrome. Journal of Clinical Endocrinology and Metabolism 200792 3579-3584.

79 Palomba S, Orio F Jr \& Falbo A. Prospective parallel randomized, doubleblind, double-dummy controlled clinical trial comparing clomiphene citrate and metformin as the first line treatment for ovulation induction in nonobese anovulatory women with polycystic ovary syndrome. Journal of Clinical Endocrinology and Metabolism 2005a $904068-4074$.

80 Neveu N, Granger L, St-Michel P \& Lavoie HB. Comparison of clomiphene citrate, metformin or the combination of both for first-line ovulation induction and achievement of pregnancy in 154 women with polycystic ovary syndrome. Fertility and Sterility 200787 113-120.

81 Johnson NP. No more surrogate end-points in randomised trials: the PCOSMIC trial protocol for women with polycystic ovary syndrome using metformin for infertility with clomiphene. Australian and New Zealand Journal of Obstetrics and Gynaecology 200646 141-145.

82 Legro RS, Barnhart HX, Schlaff WD, Carr BR, Diamond MP, Carson SA, Steinkampf MP, Coutifaris C, McGovern PG, Cataldo NA, Gosman GG, Nestler JE, Giudice LC, Leppert PC, Myers ER \& Cooperative Multicenter Reproductive Medicine Network. Clomiphene, metformin, or both for infertility in the polycystic ovary syndrome. New England Journal of Medicine 2007 $356551-566$.

83 Moll EBP, Bossuyt PM, Korevaar JC, Lambalk CB \& van der Veen F. Effect of clomifene citrate plus metformin and clomifene citrate plus placebo on induction of ovulation in women with newly diagnosed polycystic ovary syndrome: randomized double blind clinical trial. BMJ 20063321485.

84 Moll E, van der Veen F \& van Wely M. The role of metformin in polycystic ovary syndrome: a systematic review. Human Reproduction Update 200713 527-537.

85 Thessaloniki ESHRE/ASRM-Sponsored PCOS Consensus Workshop Group. Consensus on infertility treatment related to polycystic ovary syndrome. Fertility and Sterility $2008 \mathbf{8 9}$ 505-522.

86 Moll E, Korevaar J, Bossuyt P \& van der Veen F. Does adding metformin to clomifene citrate lead to higher pregnancy rates in a subset of women with polycystic ovary syndrome? Human Reproduction 200823 1830-1834.

87 Nestler JE. Metformin in the treatment of infertility in polycystic ovarian syndrome: an alternative perspective. Fertility and Sterility 200890 14-16.

88 Costello MF, Chapman M \& Conway U. A systematic review and meta-analysis of randomized controlled trials on metformin co-administration during gonadotrophin ovulation induction or IVF in women with polycystic ovary syndrome. Human Reproduction 200621 1387-1399.

89 Tang T, Glanville J, Orsi N, Barth JH \& Balen AH. The use of metformin for women with PCOS undergoing IVF treatment. Human Reproduction 200621 1416-1425.

90 Ferrara N, Frantz G, LeCouter J, Dillard-Telm L, Pham T, Draksharapu A, Giordano T \& Peale F. Differential expression of the angiogenic factor genes vascular endothelial growth factor
(VEGF) and endocrine gland-derived VEGF in normal and polycystic human ovaries. American Journal of Pathology 2003 162 1881-1893.

91 Stanek MB, Borman SM, Molskness TA, Larson JM, Stouffer RL \& Patton PE. Insulin and insulin-like growth factor stimulation of vascular endothelial growth factor production by luteinized granulosa cells: comparison between polycystic ovarian syndrome (PCOS) and non-PCOS women. Journal of Clinical Endocrinology and Metabolism 200792 2726-2733.

92 Boomsma CM, Eijkemans MJ, Hughes EG, Visser GH, Fauser BC \& Macklon NS. A meta-analysis of pregnancy outcomes in women with polycystic ovary syndrome. Human Reproduction Update $200612673-683$.

93 Glueck CJ, Sieve L, Zhu B \& Wang P. Plasminogen activator inhibitor activity, $4 G 5 \mathrm{G}$ polymorphism of the plasminogen activator inhibitor 1 gene, and first-trimester miscarriage in women with polycystic ovary syndrome. Metabolism $2006 \mathbf{5 5}$ 345-352.

94 Jakubowicz DJ, Essah PA, Seppala M, Jakubowicz S, Baillargeon JP, Koistinen R \& Nestler JE. Reduced serum glycodelin and insulin-like growth factor-binding protein-1 in women with polycystic ovary syndrome during first trimester of pregnancy. Journal of Clinical Endocrinology and Metabolism 2004 89 833-839.

95 Hu ZY, Liu YX, Liu K, Byrne S, Tor NY, Feng Q \& Ockleford CD. Expression of tissue type and urokinase type plasminogen activators as well as plasminogen activator inhibitor type-1 and type- 2 in human and rhesus monkey placenta. Journal of Anatomy 1999194 183-195.

96 Seppala M, Koistinen H, Koistinen R, Chiu PCN \& Yeung WSB. Glycosylation related actions of glycodelin: gamete, cumulus cell, immune cell and clinical associations. Human Reproduction Update 200713 275-287.

97 Sibai B, Dekker G \& Kupferminc M. Pre-eclampsia. Lancet 2005 365 785-799.

98 Forsbach-Sánchez G, Tamez-Peréz HE \& Vazquez-Lara J. Diabetes and pregnancy. Archives of Medical Research 200536 291-299.

99 Glueck CJ, Phillips H, Cameron D, Sieve-Smith L \& Wang P. Continuing metformin throughout pregnancy in women with polycystic ovary syndrome appears to safely reduce first-trimester spontaneous abortion: a pilot study. Fertility and Sterility 2001 $7546-52$.

100 Jakubowicz DJ, Iuorno MJ, Jakubowicz S, Roberts KA \& Nestler JE. Effects of metformin on early pregnancy loss in the polycystic ovary syndrome. Journal of Clinical Endocrinology and Metabolism $200287524-529$.

101 Khattab S, Mohsen IA, Foutouh IA, Ramadan A, Moaz M \& Al-Inany $H$. Metformin reduces abortion in pregnant women with polycystic ovary syndrome. Gynecological Endocrinology 200622 680-684.

102 Thatcher SS \& Jackson EM. Pregnancy outcome in infertile patients with polycystic ovary syndrome who were treated with metformin. Fertility and Sterility 200685 1002-1009.

103 Glueck CJ, Pranikoff J, Aregawi D \& Wang P. Prevention of gestational diabetes by metformin plus diet in patients with polycystic ovary syndrome. Fertility and Sterility 2008 a $89625-634$.

104 Vanky E, Salvesen KA, Heimstad R, Fougner KJ, Romundstad P \& Carlsen SM. Metformin reduces pregnancy complications without affecting androgen levels in pregnant polycystic ovary syndrome women: results of a randomized study. Human Reproduction $2004191734-1740$.

105 Glueck CJ, Goldenberg N, Pranikoff J, Loftspring M, Sieve L \& Wang P. Height, weight, and motor-social development during the first 18 months of life in 126 infants born to 109 mothers with polycystic ovary syndrome who conceived on and continued metformin through pregnancy. Human Reproduction $2004191323-1330$. 
106 Glueck CJ, Wang P, Kobayashi S, Phillips H \& Sieve-Smith L. Metformin therapy throughout pregnancy reduces the development of gestational diabetes in women with polycystic ovary syndrome. Fertility and Sterility 200277 520-525.

107 Glueck CJ, Wang P, Goldenberg N \& Sieve-Smith L. Pregnancy outcomes among women with polycystic ovary syndrome treated with metformin. Human Reproduction $2002 \quad \mathbf{1 7}$ 2858-2864.

108 Glueck CJ, Goldenberg N, Wang P, Loftspring M \& Sherman A. Metformin during pregnancy reduces insulin, insulin resistance, insulin secretion, weight, testosterone and development of gestational diabetes: prospective longitudinal assessment of women with polycystic ovary syndrome from preconception throughout pregnancy. Human Reproduction 200419 510-521.

109 Christiansen OB, Nybo Andersen AM, Bosch E, Daya S, Delves PJ, Hviid TV, Kutteh WH, Laird SM, Li T-C \& van der Ven K. Evidence-based investigations and treatments of recurrent pregnancy loss. Fertility and Sterility 200583 821-839.

110 Jakubowicz DJ, Seppala M, Jakubowicz S, Rodriguez-Armas O, Rivas-Santiago A, Koistinen H, Koistinen R \& Nestler JE. Insulin reduction with metformin increases luteal phase serum glycodelin and insulin-like growth factor-binding protein 1 concentrations and enhances uterine vascularity and blood flow in the polycystic ovary syndrome. Journal of Clinical Endocrinology and Metabolism 200186 1126-1133.

111 Palomba S, Orio F Jr, Falbo A, Russo T, Tolino A \& Zullo F. Plasminogen activator inhibitor 1 and miscarriage after metformin treatment and laparoscopic ovarian drilling in patients with polycystic ovary syndrome. Fertility and Sterility 200584 761-765.

112 Eng GS, Sheridan RA, Wyman A, Chi MM-Y, Bibee KP, Jungheim ES \& Moley KH. AMP kinase activation increases glucose uptake, decreases apoptosis, and improves pregnancy outcome in embryos exposed to high IGF-I concentrations. Diabetes $2007562228-2234$.

113 Lee MS, Kang SK, Lee BC \& Hwang WS. The beneficial effects of insulin and metformin on in vitro developmental potential of porcine oocytes and embryos. Biology of Reproduction 200573 1264-1268.

114 Nanovskaya T, Nekhayeva I, Patrikeeva S, Hankins G \& Ahmed M. Transfer of metformin across the dually perfused human placental lobule. American Journal of Obstetrics and Gynecology 2006195 1081-1085.

115 Kovo M, Haroutiunian S, Feldman N, Hoffman A \& Glezerman M. Determination of metformin transfer across the human placenta using a dually perfused ex vivo placental cotyledon model. European Journal of Obstetrics, Gynecology, and Reproductive Biology 2008136 29-33.

116 Vanky E, Zahlsen K, Spigset O \& Carlsen SM. Placental passage of metformin in women with polycystic ovary syndrome. Fertility and Sterility 200583 1575-1578.

117 Hague WM, Davoren PM, McIntyre D, Norris R \& Xiaonian XCB. Metformin crosses the placenta: a modulator for fetal insulin resistance? BMJ 2004327 880-881.

118 Charles B, Norris R, Xiao X \& Hague W. Population pharmacokinetics of metformin in late pregnancy. Therapeutic Drug Monitoring 200628 67-72.

119 Feig DS, Briggs GG \& Koren G. Oral antidiabetic agents in pregnancy and lactation: a paradigm shift? Annals of Pharmacotherapy 200741 1174-1180.

120 Brown F, Wyckoff J, Rowan J, Jovanovic L, Sacks D \& Briggs G. Metformin in pregnancy: its time has not come yet. Diabetes Care 200629 485-486.

121 Gilbert C, Valois M \& Koren G. Pregnancy outcome after firsttrimester exposure to metformin: a meta-analysis. Fertility and Sterility $2006 \mathbf{8 6} 658-663$.

122 Bolton S, Cleary B, Walsh J, Dempsey E \& Turner MJ. Continuation of metformin in the first trimester of women with polycystic ovarian syndrome is not associated with increased perinatal morbidity. European Journal of Pediatrics 2009168 203-206.
123 Diamanti-Kandarakis E, Kouli C, Tsianateli T \& Bergiele A. Therapeutic effects of metformin on insulin resistance and hyperandrogenism in polycystic ovary syndrome. European Journal of Endocrinology 1998138 269-274.

124 Ramachandran A, Snehalatha C, Mary S, Mukesh B, Bhaskar AD \& Vijay V. The Indian Diabetes Prevention Programme shows that lifestyle modification and metformin prevent type 2 diabetes in Asian Indian subjects with impaired glucose tolerance (IDPP-1). Diabetologia 200649 289-297.

125 Diabetes Prevention Program Research Group. Reduction in the incidence of type 2 diabetes with lifestyle intervention or metformin. New England Journal of Medicine 2002346 393-403.

126 Sharma ST, Wickham EP III \& Nestler E. Changes in glucose tolerance with metformin treatment in polycystic ovary syndrome: a retrospective analysis. Endocrine Practice 200713 373-379.

127 Glueck C, Goldenberg N, Sieve L \& Wang P. An observational study of reduction of insulin resistance and prevention of development of type 2 diabetes mellitus in women with polycystic ovary syndrome treated with metformin and diet. Metabolism: Clinical and Experimental $2008 \mathbf{5 7} 954-960$.

128 Moran LJ, Noakes M, Clifton PM, Wittert GA, Tomlinson L, Galletly C, Luscombe ND \& Norman RJ. Ghrelin and measures of satiety are altered in polycystic ovary syndrome but not differentially affected by diet composition. Journal of Clinical Endocrinology and Metabolism 200489 3337-3344.

129 Romualdi D, De Marinis L, Campagna G, Proto C, Lanzone A \& Guido M. Alteration of ghrelin-neuropeptide Y network in obese patients with polycystic ovary syndrome: role of hyperinsulinism. Clinical Endocrinology $200869562-567$.

130 Barber TM, Casanueva FF, Karpe F, Lage M, Franks S, McCarthy MI \& Wass JAH. Ghrelin levels are suppressed and show a blunted response to oral glucose in women with polycystic ovary syndrome. European Journal of Endocrinology 2008158 511-516.

131 Desilets AR, Dhakal-Karki S \& Dunican KC. Role of metformin for weight management in patients without type 2 diabetes. Annals of Pharmacotherapy $2008 \mathbf{4 2} 817-826$.

132 Bruno RV, de Avila MA, Neves FB, Nardi AE, Crespo CM \& Sobrinho AT. Comparison of two doses of metformin (2.5 and 1.5 $\mathrm{g} /$ day) for the treatment of polycystic ovary syndrome and their effect on body mass index and waist circumference. Fertility and Sterility $2007 \mathbf{8 8} 510-512$.

133 Harborne LR, Sattar N, Norman JE \& Fleming R. Metformin and weight loss in obese women with polycystic ovary syndrome: comparison of doses. Journal of Clinical Endocrinology and Metabolism 200590 4593-4598.

134 Trolle B, Flyvbjerg A, Kesmodel U \& Lauszus FF. Efficacy of metformin in obese and non-obese women with polycystic ovary syndrome: a randomized, double-blinded, placebo-controlled cross-over trial. Human Reproduction 200722 2967-2973.

135 Lord J, Thomas R, Fox B, Acharya U \& Wilkin T. The effect of metformin on fat distribution and the metabolic syndrome in women with polycystic ovary syndrome - a randomised, doubleblind, placebo-controlled trial. British Journal of Obstetrics and Gynaecology $2006113817-824$.

136 Pasquali R, Gambineri A, Biscotti D, Vicennati V, Gagliardi L, Colitta D, Fiorini S, Cognigni GE, Filicori M \& Morselli-Labate AM. Effect of long-term treatment with metformin added to hypocaloric diet on body composition, fat distribution, and androgen and insulin levels in abdominally obese women with and without the polycystic ovary syndrome. Journal of Clinical Endocrinology and Metabolism 200085 2767-2774.

137 Gambineri A, Pelusi C, Genghini S, Morselli-Labate AM, Cacciari M, Pagotto U \& Pasquali R. Effect of flutamide and metformin administered alone or in combination in dieting obese women with polycystic ovary syndrome. Clinical Endocrinology $200460241-249$.

138 Gambineri A, Patton L, Vaccina A, Cacciari M, MorselliLabate AM, Cavazza C, Pagotto U \& Pasquali R. Treatment with flutamide, metformin, and their combination added to a 
hypocaloric diet in overweight-obese women with polycystic ovary syndrome: a randomized, 12-month, placebo-controlled study. Journal of Clinical Endocrinology and Metabolism 200691 3970-3980.

139 Tang T, Glanville J, Hayden CJ, White D, Barth JH \& Balen AH. Combined lifestyle modification and metformin in obese patients with polycystic ovary syndrome. A randomized, placebocontrolled, double-blind multicentre study. Human Reproduction $2006 b 2180-89$.

140 Spranger J, Möhlig M, Wegewitz U, Ristow M, Pfeiffer AF, Schill T, Schlösser HW, Brabant G \& Schöfl C. Adiponectin is independently associated with insulin sensitivity in women with polycystic ovary syndrome. Clinical Endocrinology 2004 $61738-746$.

141 Romualdi D, Campagna G, Selvaggi L Jr, Cento R, Proto C, Lanzone A \& Guido M. Metformin treatment does not affect total leptin levels and free leptin index in obese patients with polycystic ovary syndrome. Fertility and Sterility 2008b 89 1273-1276.

142 Sahin Y, Unluhizarci K, Yilmazsoy A, Yikilmaz A, Aygen E \& Kelestimur F. The effects of metformin on metabolic and cardiovascular risk factors in nonobese women with polycystic ovary syndrome. Clinical Endocrinology 200767 904-908.

143 Orio F, Manguso F, Di Biase S, Falbo A, Giallauria F, Labella D, Tolino A, Lombardi G, Colao A \& Palomba S. Metformin administration improves leukocyte count in women with polycystic ovary syndrome: a 6-month prospective study. European Journal of Endocrinology 2007157 69-73.

144 Morin-Papunen L, Rautio K, Ruokonen A, Hedberg P, Puukka M \& Tapanainen JS. Metformin reduces serum C-reactive protein levels in women with polycystic ovary syndrome. Journal of Clinical Endocrinology and Metabolism 200388 4649-4654.

145 Velazquez EM, Mendoza SG, Wang P \& Glueck CJ. Metformin therapy is associated with a decrease in plasma plasminogen activator inhibitor-1, lipoprotein(a), and immunoreactive insulin levels in patients with the polycystic ovary syndrome. Metabolism $199746454-457$.

146 Romualdi D, Costantini B, Selvaggi L, Giuliani M, Cristello F, Macrì F, Bompiani A, Lanzone A \& Guido M. Metformin improves endothelial function in normoinsulinemic PCOS patients: a new prospective. Human Reproduction 200823 2127-2133.

147 Diamanti-Kandarakis E, Alexandraki K, Protogerou A, Piperi C, Papamichael C, Aessopos A, Lekakis J \& Mavrikakis M. Metformin administration improves endothelial function in women with polycystic ovary syndrome. European Journal of Endocrinology 2005152 749-756.

148 Orio F Jr, Palomba S, Cascella T, De Simone B, Manguso F, Savastano S, Russo T, Tolino A, Zullo F, Lombardi G, Azziz R \& Colao A. Improvement in endothelial structure and function after metformin treatment in young normal-weight women with polycystic ovary syndrome: results of a 6-month study. Journal of Clinical Endocrinology and Metabolism 200590 6072-6076.

149 Diamanti-Kandarakis E, Spina G, Kouli C \& Migdalis I. Increases endothelin-1 levels in women with polycystic ovary syndrome and the beneficial effect of metformin therapy. Journal of Clinical Endocrinology and Metabolism 200186 4666-4673.

150 Topcu S, Tok D, Caliskan M, Ozcimen EE, Gullu H, Uckuyu A, Erdogan D, Zeyneloglu H \& Muderrisoglu H. Metformin therapy improves coronary microvascular function in patients with polycystic ovary syndrome and insulin resistance. Clinical Endocrinology 200665 75-80.

151 Bonetti PO, Lerman LO \& Lerman A. Endothelial dysfunction: a marker of atherosclerotic risk. Arteriosclerosis, Thrombosis, and Vascular Biology 200323 168-175.

152 Britten MB, Zeiher AM \& Schachinger V. Microvascular dysfunction in angiographically normal or mildly diseased coronary arteries predicts adverse cardiovascular long-term outcome. Coronary Artery Disease 200415 259-264.

153 Dokras A, Jagasia DH, Maifeld M, Sinkey CA, VanVoorhis BJ \& Haynes WG. Obesity and insulin resistance but not hyperandrogenism mediates vascular dysfunction in women with polycystic ovary syndrome. Fertility and Sterility $2006 \mathbf{8 6}$ 1702-1709.

154 Sorensen MB, Franks S, Robertson C, Pennell DJ \& Collins P. Severe endothelial dysfunction in young women with polycystic ovary syndrome is only partially explained by known cardiovascular risk factors. Clinical Endocrinology $2006 \mathbf{6 5}$ 655-659.

155 Nácul AP, Andrade CD, Schwarz P, de Bittencourt PI Jr \& Spritzer PM. Nitric oxide and fibrinogen in polycystic ovary syndrome: associations with insulin resistance and obesity. European Journal of Obstetrics, Gynecology, and Reproductive Biology 2007133 191-196.

156 Paradisi G, Steinberg HO, Hempfling A, Cronin J, Hook G, Shepard MK \& Baron AD. Polycystic ovary syndrome is associated with endothelial dysfunction. Circulation 2001103 1410-1415.

157 Kravariti M, Naka KK, Kalantaridou SN, Kazakos N, Katsouras CS, Makrigiannakis A, Paraskevaidis EA, Chrousos GP, Tsatsoulis A \& Michalis LK. Predictors of endothelial dysfunction in young women with polycystic ovary syndrome. Journal of Clinical Endocrinology and Metabolism 2005 90 5088-5095.

158 Orio F Jr, Palomba S, Cascella T, De Simone B, Di Biase S, Russo T, Labella D, Zullo F, Lombardi G \& Colao A. Early impairment of endothelial structure and function in young normal-weight women with polycystic ovary syndrome. Journal of Clinical Endocrinology and Metabolism $2004894588-4593$.

159 Ozgurtas T, Oktenli C, Dede M, Tapan S, Kenar L, Sanisoglu SY, Yesilova Z, Yenen MC, Erbil MK \& Baser I. Metformin and oral contraceptive treatments reduced circulating asymmetric dimethylarginine (ADMA) levels in patients with polycystic ovary syndrome (PCOS). Atherosclerosis 2008200 336-344.

160 Heutling D, Schulz H, Nickel I, Kleinstein J, Kaltwasser P, Westphal S, Mittermayer F, Wolzt M, Krzyzanowska K, Randeva H, Schernthaner G \& Lehnert H. Asymmetrical dimethylarginine, inflammatory and metabolic parameters in women with polycystic ovary syndrome before and after metformin treatment. Journal of Clinical Endocrinology and Metabolism 200893 82-90.

161 Diamanti-Kandarakis E, Alexandraki K, Piperi C, Aessopos A, Paterakis T, Katsikis I \& Panidis D. Effect of metformin administration on plasma advanced glycation end product levels in women with polycystic ovary syndrome. Metabolism $2007 \mathbf{5 6}$ 129-134.

162 Diamanti-Kandarakis E, Katsikis I, Piperi C, Kandaraki E, Piouka A, Papavassiliou AG \& Panidis D. Increased serum advanced glycation end products is a distinct finding in lean women with PCOS. Clinical Endocrinology 200869 634-641.

163 De Jager J, Kooy A, Lehert P, Bets D, Wulffelé MG, Teerlink T, Scheffer PG, Schalkwijk CG, Donker AJ \& Stehouwer CD. Effects of short-term treatment with metformin on markers of endothelial function and inflammatory activity in type 2 diabetes mellitus: a randomized, placebo-controlled trial. Journal of Internal Medicine 2005257 100-109.

164 Jadhav S, Ferrell W, Greer IA, Petrie JR, Cobbe SM \& Sattar N. Effects of metformin on microvascular function and exercise tolerance in women with angina and normal coronary arteries: a randomized, double-blind, placebo-controlled study. Journal of the American College of Cardiology 200648 956-963.

165 Morrow VA, Foufelle F, Connell JM, Petrie JR, Gould GW \& Salt IP. Direct activation of AMP-activated protein kinase stimulates nitric-oxide synthesis in human aortic endothelial cells. Journal of Biological Chemistry 2003278 31629-31639.

166 Nelson SM \& Fleming RF. The preconceptual contraception paradigm: obesity and infertility. Human Reproduction 200722 912-915.

167 Fleming R, Hopkinson ZE, Wallace AM, Greer IA \& Sattar N. Ovarian function and metabolic factors in women with 
oligomenorrhea treated with metformin in a randomized double blind placebo-controlled trial. Journal of Clinical Endocrinology and Metabolism 200287 569-574.

168 Maciel GA, Soares Junior JM, Alves da Motta EL, Abi Haidar M, de Lima GR \& Baracat EC. Nonobese women with polycystic ovary syndrome respond better than obese women to treatment with metformin. Fertility and Sterility $2004 \mathbf{8 1}$ 355-360.

169 Baillargeon JP, Jakubowicz DJ, Iuorno MJ, Jakubowicz S \& Nestler JE. Effects of metformin and rosiglitazone, alone and in combination, in nonobese women with polycystic ovary syndrome and normal indices of insulin sensitivity. Fertility and Sterility 200482 893-902.

170 Onalan G, Goktolga U, Ceyhan T, Bagis T, Onalan R \& Pabucxcu R. Predictive value of glucose-insulin ratio in PCOS and profile of women who will benefit from metformin therapy: obese, lean, hyper or normoinsulinemic? European Journal of Obstetrics, Gynecology, and Reproductive Biology 2005123 204-211.

171 Genazzani AD, Lanzoni C, Ricchieri F, Baraldi E, Casarosa E \& Jasonni VM. Metformin administration is more effective when nonobese patients with polycystic ovary syndrome show both hyperandrogenism and hyperinsulinemia. Gynecological Endocrinology 200723 146-152.

172 Legro RS, Barnhart HX, Schlaff WD, Carr BR, Diamond MP, Carson SA, Steinkampf MP, Coutifaris C, McGovern PG, Cataldo NA, Gosman GG, Nestler JE, Giudice LC, Ewens KG, Spielman RS, Leppert PC, Myers ER \& for the Reproductive Medicine Network. Ovulatory response to treatment of polycystic ovary syndrome is associated with a polymorphism in the STK11 gene. Reproductive Medicine Network 2007. Journal of Clinical Endocrinology and Metabolism 200893 792-800.

173 Palomba S, Falbo A, Orio F Jr, Tolino A \& Zullo F. Efficacy predictors for metformin and clomiphene citrate treatment in anovulatory infertile patients with polycystic ovary syndrome. Fertility and Sterility $2008912557-2567$.

174 Tan S, Hahn S, Benson S, Dietz T, Lahner H, Moeller LC, Schmidt M, Elsenbruch S, Kimmig R, Mann K \& Janssen OE. Metformin improves polycystic ovary syndrome symptoms irrespective of pre-treatment insulin resistance. European Journal of Endocrinology 2007157 669-676.

175 Diamanti-Kandarakis E, Kouli C, Alexandraki K \& Spina G. Failure of mathematical indices to accurately assess insulin resistance in lean, overweight, or obese women with polycystic ovary syndrome. Journal of Clinical Endocrinology and Metabolism 200489 1273-1276.

176 Coyral-Castel S, Tosca L, Ferreira G, Jeanpierre E, Rame C, Lomet D, Caraty A, Monget P, Chabrolle C \& Dupont J. The effect of AMPK activation on GnRH secretion in GT1-7 cells and its potential role in hypothalamic regulation of the oestrous cyclicity in rats. Journal of Neuroendocrinology 200820 335-346.

177 Moghetti P, Castello R, Negri C, Tosi F, Perrone F, Caputo M, Zanolin E \& Muggeo M. Metformin effects on clinical features, endocrine and metabolic profiles, and insulin sensitivity in polycystic ovary syndrome: a randomized, doubleblind, placebocontrolled 6-month trial, followed by open, long-term clinical evaluation. Journal of Clinical Endocrinology and Metabolism 2000 85 139-146.

178 Azziz R, Carmina E, Dewailly D, Diamanti-Kandarakis E, EscobarMorreale HF, Futterweit W, Janssen OE, Legro RS, Norman RJ, Taylor AE, Witchel SF \& Task Force on the Phenotype of the Polycystic Ovary Syndrome of the Androgen Excess and PCOS Society. The Androgen Excess and PCOS Society criteria for the polycystic ovary syndrome: the complete task force report. Fertility and Sterility 200991 456-488.
179 Morin-Papunen LC, Vauhkonen I, Koivunen RM, Ruokonen A, Martikainen HK \& Tapanainen JS. Endocrine and metabolic effects of metformin versus ethinyl estradiol-cyproterone acetate in obese women with polycystic ovary syndrome: a randomized study. Journal of Clinical Endocrinology and Metabolism 200085 3161-3168.

180 Kolodziejczyk B, Duleba AJ. Spaczynski RZ \& Pawelczyk L. Metformin therapy decreases hyperandrogenism and hyperinsulinaemia in women with polycystic ovary syndrome. Fertility and Sterility 200073 1149-1154.

181 Elter K, Imir G \& Durmusoglu F. Clinical, endocrine and metabolic effects of metformin added to ethinyl estradiolcyproterone acetate in non-obese women with polycystic ovarian syndrome: a randomized controlled study. Human Reproduction 200217 1729-1737.

182 Kelly CJ \& Gordon D. The effect of metformin on hirsutism in polycystic ovary syndrome. European Journal of Endocrinology $2002147217-221$.

183 Harborne L, Fleming R, Lyall H, Sattar N \& Norman J. Metformin or antiandrogen in the treatment of hirsutism in polycystic ovary syndrome. Journal of Clinical Endocrinology and Metabolism 2003 $884116-4123$.

184 Cosma M, Swiglo BA, Flynn DN, Kurtz DM, LaBella ML, Mullan RJ, Elamin MB, Erwin PJ \& Montori VM. Insulin sensitizers for the treatment of hirsutism: a systematic review and metaanalyses of randomized controlled trials. Journal of Clinical Endocrinology and Metabolism 200893 1135-1142.

185 Martin KA, Chang RJ, Ehrmann DA, Ibanez L, Lobo RA, Rosenfield RL, Shapiro J, Montori VM \& Swiglo BA. Evaluation and treatment of hirsutism in premenopausal women: an endocrine society clinical practice guideline. Journal of Clinical Endocrinology and Metabolism 200893 1105-1120.

186 Costello MF, Shrestha B, Eden J, Johnson NP \& Sjoblom P. Metformin versus oral contraceptive pill in polycystic ovary syndrome: a Cochrane review. Human Reproduction 200722 1200-1209.

187 Luque-Ramirez M, Alvarez-Blasco F, Botella-Carretero JI, Martmez-Bermejo E, Lasuncion MA \& Escobar-Morreale HF. Comparison of ethinyl-estradiol plus cyproterone acetate versus metformin effects on classic metabolic cardiovascular risk factors in women with the polycystic ovary syndrome. Journal of Clinical Endocrinology and Metabolism 200792 2453-2461.

188 Meyer C, McGrath BP \& Teede HJ. Effects of medical therapy on insulin resistance and the cardiovascular system in polycystic ovary syndrome. Diabetes Care 200730 471-478.

189 Ting RZ, Szeto CC, Chan MH \& Chow KM. Risk factors of vitamin B12 deficiency in patients receiving metformin. Archives of Internal Medicine 2006166 1975-1979.

190 Setter SM, Iltz JL, Thams J \& Campbell RK. Metformin hydrochloride in the treatment of type 2 diabetes mellitus: a clinical review with a focus on dual therapy. Clinical Therapeutics 200325 2991-3026.

191 Cryer DR, Nicholas SP, Henry DH, Mills DJ \& Stadel BV. Comparative outcomes study of metformin intervention versus conventional approach the COSMIC Approach Study. Diabetes Care 200528 539-543.

192 Salpeter S, Greyber E, Pasternak G \& Salpeter E. Risk of fatal and non-fatal lactic acidosis with metformin in type 2 diabetes. Archives of Internal Medicine 2003163 2294-2602.

Received 5 October 2009

Accepted 14 October 2009 